*For correspondence:

saige.rutherford@donders.ru.nl; andre.marquand@donders.ru.nl

${ }^{\dagger}$ These authors contributed equally to this work

\title{
Charting Brain Growth and Aging at High Spatial Precision
}

3 Saige Rutherford ${ }^{1,2,3^{*}}$, Charlotte Fraza ${ }^{1,2}$, Richard Dinga ${ }^{1,2}$, Seyed Mostafa Kia ${ }^{1,2,4}$, 4homas Wolfers ${ }^{5,6}$, Mariam Zabihi ${ }^{1,2}$, Pierre Berthet ${ }^{5,6}$, Amanda Worker ${ }^{7}$, Serena Verdi $^{8,9}$, Derek Andrews ${ }^{10}$, Laura Han ${ }^{11,12}$, Johanna Bayer ${ }^{13,14}$, Paola Dazzan ${ }^{7,15}$, Phillip McGuire ${ }^{16}$, Roel T. Mocking ${ }^{17}$, Aaart Schene ${ }^{1,18}$, Brenda W. Pennix ${ }^{11,12}$, Chandra Sripada ${ }^{3}$, Ivy F. Tso ${ }^{3}$, Elizabeth R. Duval ${ }^{3}$, Soo-Eun Chang ${ }^{3}$, Mary Heitzeg ${ }^{3}$, S. Alexandra Burt ${ }^{19}$, Luke Hyde $^{20}$, David Amaral ${ }^{10}{ }^{\text {, Christine Wu Nordahl }}{ }^{10}$, Ole A. Andreasssen $^{6,21}$, Lars T. Westlye ${ }^{5,6,21}$, Roland Zahn ${ }^{22}$, Henricus G. Ruhe ${ }^{1,18 \dagger}$, Christian Beckmann ${ }^{1,2,23 \dagger}$, Andre F. Marquand ${ }^{1,2^{* \dagger}}$

${ }_{11}{ }^{1}$ Donders Institute for Brain, Cognition, and Behavior, Radboud University, Nijmegen, 12 the Netherlands; ${ }^{2}$ Department of Cognitive Neuroscience, Radboud University Medical

Center, Nijmegen, the Netherlands; ${ }^{3}$ Department of Psychiatry, University of Michigan, Ann Arbor, MI, United States; ${ }^{4}$ Department of Psychiatry, Utrecht University Medical Center, Utrecht, the Netherlands; ${ }^{5}$ Department of Psychology, University of Oslo, Oslo, Norway; ${ }^{6}$ Norwegian Center for Mental Disorders Research (NORMENT), University of Oslo, and Oslo University Hospital, Oslo, Norway; ${ }^{7}$ Department of Psychological Medicine, Institute of Psychiatry, Psychology and Neuroscience, King's College London, London, United Kingdom; ${ }^{8} 8$ Centre for Medical Image Computing, Medical Physics and Biomedical Engineering, University College London, London, United Kingdom;

${ }^{9}$ Dementia Research Centre, UCL Queen Square Institute of Neurology, London, United Kingdom; ${ }^{10}$ The Medical Investigation of Neurodevelopmental Disorders (MIND) Institute and Department of Psychiatry and Behavioral Sciences, UC Davis School of Medicine, University of California Davis, Sacramento, CA, United States; ${ }^{11}$ Amsterdam UMC, Vrije Universiteit, Psychiatry, Amsterdam Public Health Research Institute, Amsterdam, the Netherlands; ${ }^{12} \mathrm{GGZ}$ inGeest, Amsterdam Neuroscience, Amsterdam, the Netherlands; ${ }^{13}$ Centre for Youth Mental Health, University of Melbourne, Melbourne, Australia; ${ }^{14}$ Orygen Youth Health, Melbourne, Australia; ${ }^{15}$ National Institute for Health Research Mental Health Biomedical Research Centre, South London and Maudsley National Health Service Foundation Trust and King's College, London, United Kingdom; ${ }^{16}$ Department of Psychosis Studies, Institute of Psychiatry, King's College, London, United Kingdom; ${ }^{17}$ Department of Psychiatry, Amsterdam UMC, Location AMC, Amsterdam, the Netherlands; ${ }^{18}$ Department of Psychiatry, Radboud University Medical Center, Nijmegen, the Netherlands; ${ }^{19}$ Department of Psychology, Michigan State University, East Lansing, MI, United States; ${ }^{20}$ Department of Psychology, University of Michigan, Ann Arbor, MI, United States; ${ }^{21} \mathrm{KG}$ Jebsen Centre for Neurodevelopmental Disorders Research, Institute if Clinical Medicine, University of Oslo, Oslo, Norway; ${ }^{22}$ Centre for Affective Disorders at the Institute of Psychiatry, King's College, London, United Kingdom; ${ }^{23}$ Centre for Functional MRI of the Brain (FMRIB), Nuffield Department of Clinical Neurosciences, Wellcome Centre for Integrative Neuroimaging, University of Oxford, Oxford, United Kingdom 
Abstract Defining reference models for population variation, and the ability to study individual deviations is essential for understanding inter-individual variability and its relation to the onset and progression of medical conditions. In this work, we assembled a reference cohort of neuroimaging data from 82 sites ( $N=58,836$; ages 2-100) and use normative modeling to characterize lifespan trajectories of cortical thickness and subcortical volume. Models are validated against a manually quality checked subset $(\mathrm{N}=24,354)$ and we provide an interface for transferring to new data sources. We showcase the clinical value by applying the models to a transdiagnostic psychiatric sample $(\mathrm{N}=1,985)$, showing they can be used to quantify variability underlying multiple disorders whilst also refining case-control inferences. These models will be augmented with additional samples and imaging modalities as they become available. This provides a common reference platform to bind results from different studies and ultimately paves the way for personalized clinical decision making.

\section{Introduction}

Since their introduction more than a century ago, normative growth charts have become fundamental tools in pediatric medicine and also in many other areas of anthropometry (Cole (2012)). They provide the ability to quantify individual variation against centiles of variation in a reference population, which shifts focus away from group-level (e.g., case-control) inferences to the level of the individual. This idea been adopted and generalized in clinical neuroimaging and normative modelling is now established as an effective technique for providing inferences at the level of the individual in neuroimaging studies (Marquand et al. (2016, 2019)).

Although normative modelling can be used to estimate many different kinds of mappings - for example between behavioral scores and neurobiological readouts - normative models of brain development and aging are appealing considering that many brain disorders are grounded in atypical trajectories of brain development (Insel (2014)) and the association between cognitive decline and brain tissue in ageing and neurodegenerative diseases (Jack et al. (2010); Karas et al. (2004)). Indeed, normative modelling has been applied in many different clinical contexts, including charting the development of infants born pre-term (Dimitrova et al. (2020)) and dissecting the biological heterogeneity across cohorts of individuals with different brain disorders including schizophrenia, bipolar disorder, autism and attention deficit/hyperactivity disorder (Bethlehem et al. (2020); Wolfers et al. (2021); Zabihi et al. (2019)).

A hurdle to the widespread application of normative modelling is a lack of well-defined reference models to quantify variability across the lifespan and to compare results from different studies. Such models should: (i) accurately model population variation across large samples; (ii) be derived from widely accessible measures; (iii) provide the ability to be updated as additional data come on-line and (vi) be supported by easy-to-use software tools. In addition, they should quantify brain development and ageing at a high spatial resolution, so that different patterns of atypicality can be used to stratify cohorts and predict clinical outcomes with maximum precision. The purpose of this work is to introduce a set of reference models that satisfy these criteria.

To this end, we assemble a large neuroimaging dataset (Table 1) from 58,836 individuals across 82 scan sites covering the human lifespan (aged 2-100, Figure 1A) and fit normative models for cortical thickness and subcortical volumes derived from Freesurfer (version 6.0). We show the clinical utility of these models in a large transdiagnostic psychiatric sample $(N=1,985)$. To maximize the utility of this contribution, we distribute model coefficients freely along with a set of software tools to enable researchers to derive subject-level predictions for new datasets against a set of common reference models. 
Table 1. Sample Description and Demographics. $\mathrm{QQC}$ refers to the manual quality checked subset of the full sample. 'All' rows = Train + Test. Clinical refers to the transdiagnostic psychiatric sample (diagnostic details in Figure 2A).

\begin{tabular}{|c|l|l|l|l|l|}
\hline & & $\mathbf{N}$ (subjects) & $\mathbf{N}$ (sites) & Sex (\%F, \%M) & Age (Mean, s.d) \\
\hline Full & All & 58,836 & 82 & & \\
\hline & Training set & 29,418 & 82 & $51.1,48.9$ & $46.9,24.4$ \\
\hline & Test set & 29,416 & 82 & $50.9,49.1$ & $46.9,24.4$ \\
\hline mQC & All & 24,354 & 59 & & \\
\hline & Training set & 12,177 & 59 & $50.2,49.8$ & $30.2,24.1$ \\
\hline & Test set & 12,177 & 59 & $50.4,49.4$ & $30.1,24.2$ \\
\hline Clinical & Test set & 1,985 & 24 & $38.9,61.1$ & $30.5,14.1$ \\
\hline
\end{tabular}

\section{Results}

We split the available data into training and test sets, stratifying the split by site, such that all sites are equally represented in the training and test sets (Table 1, Supplementary Table 2, Supplementary Table 3, and Supplementary Table 4). After careful automated and manual quality checking procedures (see methods), we then fit a normative model using a set of covariates (age, gender, and fixed effects for site) to predict cortical thickness and subcortical volume for each parcel in a high resolution atlas derived from the Freesurfer software package (Destrieux et al. (2010)). We employed a warped Bayesian linear regression model so as to accurately model both non-linear effects and non-Gaussian distribution of the imaging phenotype (Fraza et al. (2021)), whilst accounting for the well-known effects of different scanners on neuroimaging data (Bayer et al. (2021); Kia et al. (2021)). These models are summarized in Figure 3, Supplementary Table 5, Supplementary Table 6, Supplementary Table 7, and Supplementary Table 8.

We validate our models with several careful procedures: first, we report out of sample metrics; second, we perform a supplementary analysis on a subset of participants for whom input data had undergone manual quality checking by an expert rater (Table 1 - mQC). Third, each model fit was evaluated using metrics (Figure 3, Supplementary Table 5, Supplementary Table 6, Supplementary Table 7, and Supplementary Table 8) that quantify central tendency and distributional accuracy (Dinga et al. (2021); Fraza et al. (2021)). We also estimated separate models for males and females, which indicate that sex effects are adequately modeled using a global offset. Finally, to facilitate independent validation, we packaged pretrained models and code for transferring to new samples into an open resource for use by the community and demonstrate how to transfer the models to new samples (i.e., data not present in the initial training set).

Our models provide the opportunity for mapping the diverse trajectories of different brain areas. Several examples are shown in Figure $1 \mathrm{C}$ and $\mathrm{D}$ which align with known patterns of development and aging (Ducharme et al. (2016); Gogtay et al. (2004); Tamnes et al. (2010)). Moreover, across the cortex and subcortex our model fits well, explaining up to $80 \%$ of the variance (minimum 12\%) out of sample (Figure 3, Supplementary Table 5, Supplementary Table 6, Supplementary Table 7, and Supplementary Table 8 for full details).

A goal of this work is to develop normative models that can be applied to many different clinical conditions. To showcase this, we apply the model to a transdiagnostic psychiatric cohort (Table 1 - Clinical; Figure 2A) resulting in personalized, whole-brain deviation maps that can be used to understand inter-individual variability (e.g., for stratification) and to quantify group separation (e.g., case-control effects). To demonstrate this, for each clinical group, we summarized the individual deviations within that group by computing the proportion of subjects that have deviations in each region and compare to matched (same sites) controls in the test set (Figure 2B-C). Additionally, we performed case-control comparisons on the raw cortical thickness and subcortical volumes, and on the deviation maps (Figure 2D), again against a matched sample from the test set. This demonstrates the advantages of using normative models for investigating individual differences in 
bioRxiv preprint doi: https://doi.org/10.1101/2021.08.08.455487; this version posted August 9, 2021. The copyright holder for this preprint (which was not certified by peer review) is the author/funder, who has granted bioRxiv a license to display the preprint in perpetuity. It is made available under aCC-BY 4.0 International license.

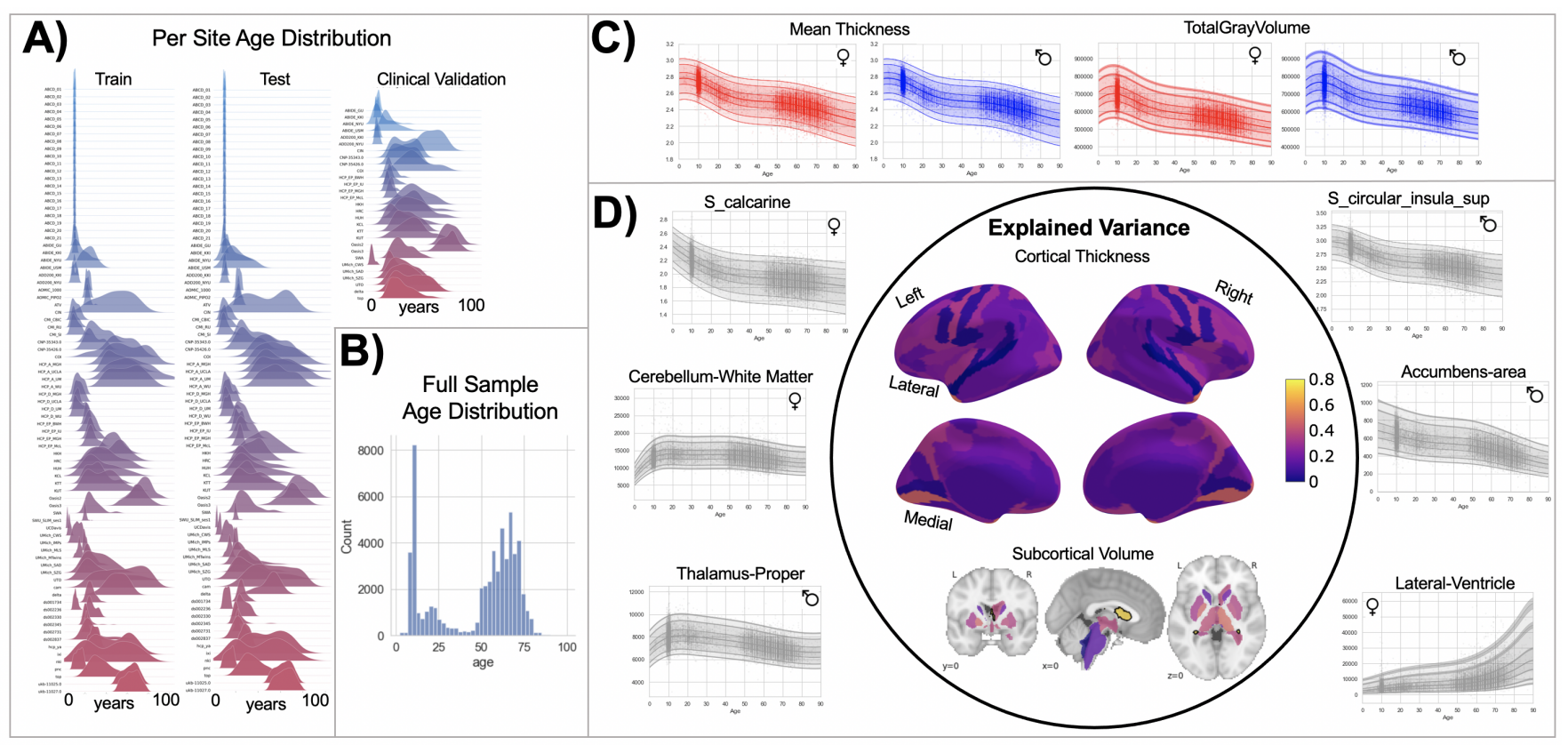

Figure 1. Normative Model Overview. A) Age distribution (x-axis) of each site (y-axis) in the full model train and test sets. B) Age distribution of each site in the clinical test set. C-D) Examples of lifespan trajectories of brain regions. Age is shown on $\mathrm{x}$-axis and predicted thickness (or volume) values are on the $y$-axis. Centiles of variation are plotted for each region. In panel $\mathrm{C}$, we show that sex differences between females (red) and males (blue) are most pronounced when modeling large scale features such as mean cortical thickness across the entire cortex or total gray matter volume. These sex differences manifest as a shift in the mean in that the shape of these trajectories is the same for both sexes, as determined by sensitivity analyses where separate normative models were estimated for each sex. The explained variance (in full test set) of the whole cortex and subcortex is highlighted inside the circle of panel D. All plots within the circle share the same color scale. E) The distribution of evaluation metrics in the full test set, separated into left and right hemispheres and subcortical regions, with the skew and excess kurtosis being measures that depict the accuracy of the estimated shape of the model, ideally both of these would be around zero.

psychiatry, i.e., quantifying clinically relevant information at the level of each individual. For most diagnostic groups, the z-statistics derived from the normative deviations also provided stronger case-control effects than the raw data. This shows the importance of accurate modeling of population variance across multiple clinically relevant dimensions. The individual-level deviations provide complimentary information to the group effects, which aligns with previous work (Wolfers et al. (2020); Zabihi et al. (2020); Wolfers et al. (2018)). We note that a detailed description of the clinical significance of our findings is beyond the scope of this work and will be presented separately.

\section{Discussion}

In this work we create lifespan brain charts of cortical thickness and subcortical volume derived from structural MRI, to serve as reference models. Multiple datasets were joined to build a megasite lifespan reference cohort to provide good coverage of the lifespan. We applied the reference cohort models to clinical datasets and demonstrate the benefits of normative modeling in addition to standard case-control comparisons. All models, including documentation and code, are made available to the research community.

We identify three main strengths of our approach. First, our large lifespan dataset provides high anatomical specificity, necessary for discriminating between conditions, predicting outcomes, and stratifying subtypes. Second, our models are flexible in that they can model non-Gaussian distributions, can easily be transferred to new sites, and are built on validated analytical techniques and software tools (Fraza et al. (2021); Kia et al. (2021); Marquand et al. (2019)). Third, we show the general utility of this work in that it provides the ability to map individual variation whilst also improving case control inferences across multiple disorders.

In recent work, a large consortium established lifespan brain charts that are complementary to 
bioRxiv preprint doi: https://doi.org/10.1101/2021.08.08.455487; this version posted August 9, 2021. The copyright holder for this preprint (which was not certified by peer review) is the author/funder, who has granted bioRxiv a license to display the preprint in perpetuity. It is made available under aCC-BY 4.0 International license.

A) Clinical Validation Sample Description

\begin{tabular}{|l|c|c|c|c|}
\hline & N (subjects) & N (sites) & Sex (F/M) & Age (m, s.d) \\
\hline Attention Deficit Disorder (ADHD) & 111 & 4 & $71 / 40$ & $17.6,12.4$ \\
\hline Autism Spectrum Disorder (ASD) & 450 & 6 & $389 / 61$ & $19.1,11.1$ \\
\hline Early Psychosis (EP) & 207 & 5 & $112 / 165$ & $29.4,10.7$ \\
\hline Schizophrenia (SZ) & 469 & 8 & $193 / 276$ & $31.9,9.5$ \\
\hline Bipolar Disorder (BD) & 249 & 4 & $138 / 111$ & $34.5,10.9$ \\
\hline Major Depression Disorder (MDD) & 499 & 9 & $260 / 239$ & $40.2,13.4$ \\
\hline
\end{tabular}

B) Percent of Individuals with Extreme Positive Deviations (Z-score > 2)

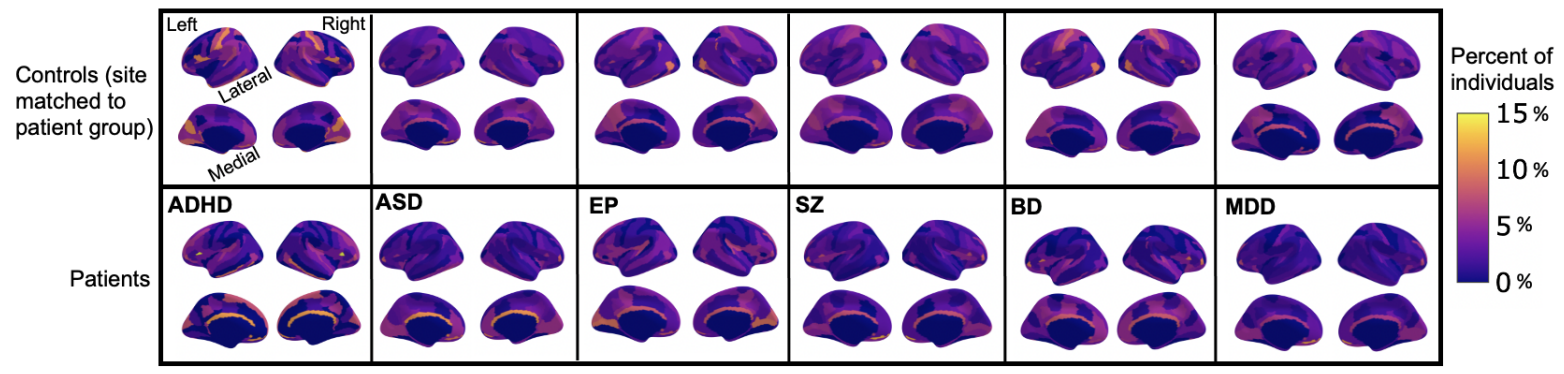

C) Percent of Individuals with Extreme Negative Deviations (Z-score <-2)

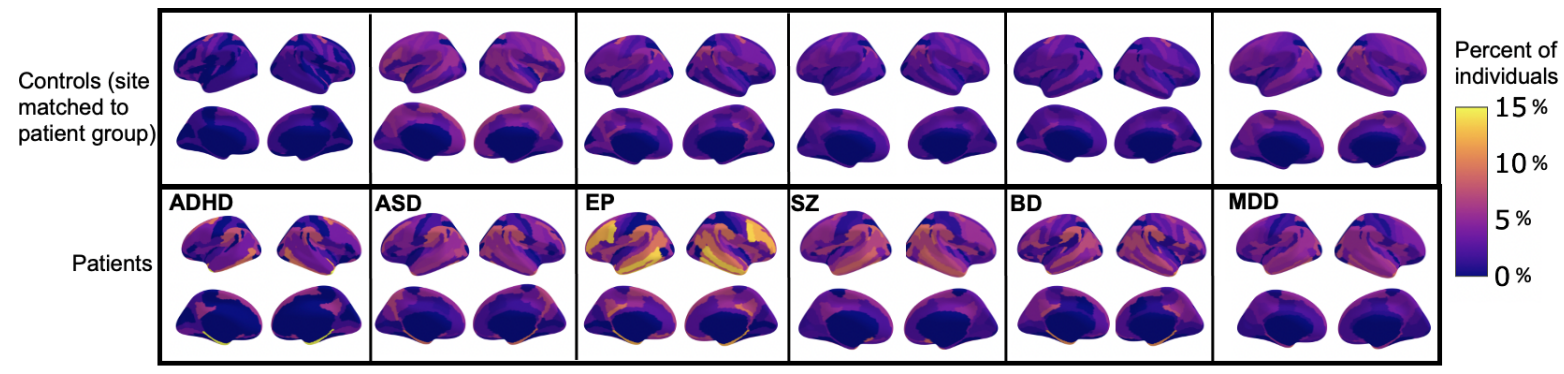

D) Control vs. Patient Univariate T-Tests

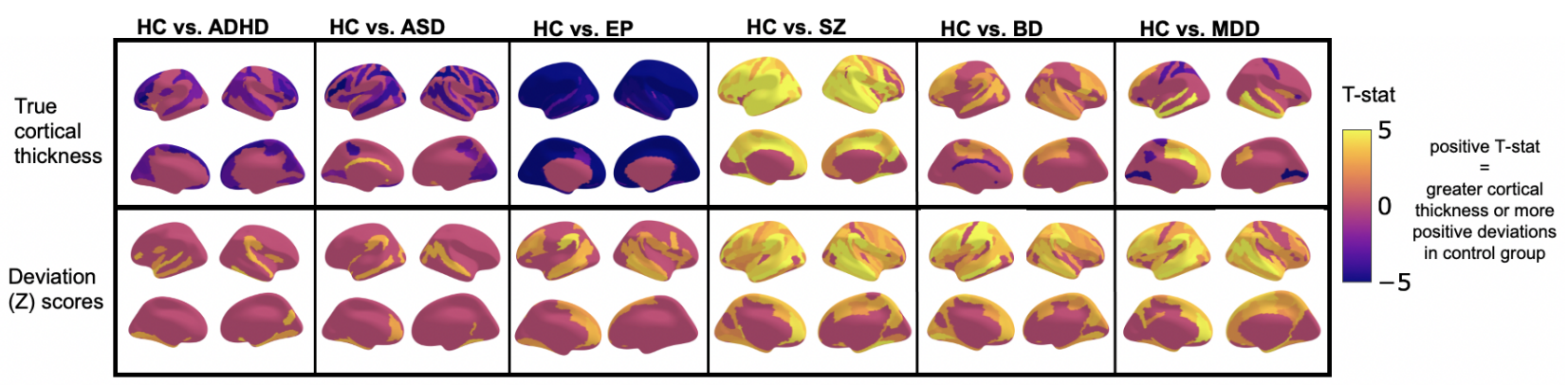

Figure 2. Normative Modeling in Clinical Cohorts. Reference brain charts were transferred to several clinical samples (panel A). Patterns of extreme deviations were summarized for each clinical group and compared to matched control groups (from the same sites). Panel B) shows extreme positive deviations (thicker/larger than expected) and panel C) shows the extreme negative deviation (thinner/smaller than expected) patterns. Panel $D$ ) shows the significant (FDR corrected $\mathrm{p}<0.05$ ) results of classical case-control methods (mass-univariate t-tests) on the true cortical thickness data (top row) and on the deviations scores (bottom row). There is unique information added by each approach which becomes evident when noticing the maps in panels B-D are not identical. ADHD=Attention Deficit Hyperactive Disorder, ASD=Autism Spectrum Disorder, EP=Early Psychosis, SZ=Schizophrenia, BD=Bipolar Disorder, MDD=Major Depressive Disorder.

149 our approach (Bethlehem et al. (2021)). Benefits of their work include the use of a large sample 150 and good coverage of the peri-natal life stages. This was used to provide estimates of brain growth 151 in terms of global features (e.g., brain volume), which is valuable for applications where quantify152 ing global brain development or ageing is of interest but has limited spatial precision. In contrast, 


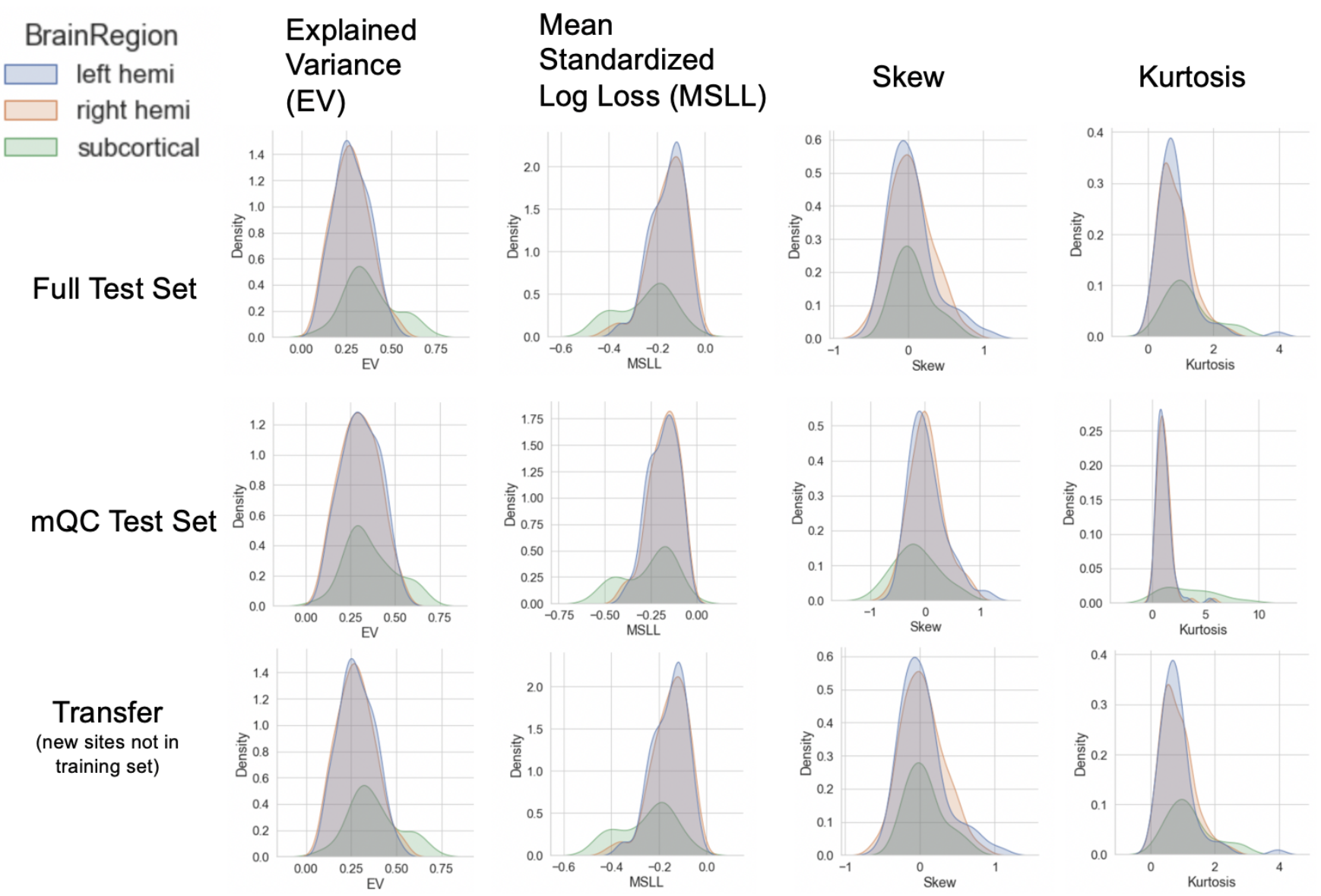

Figure 3. Evaluation Metrics Across All Test Sets. The distribution of evaluation metrics in 3 different test sets (full, mQC, and Transfer) separated into left and right hemispheres and subcortical regions, with the skew and excess kurtosis being measures that depict the accuracy of the estimated shape of the model, ideally both of these would be around zero.

153

154

155

156

157

158

159

160

161

162

163

164

165

166

167

168

169

170

171 we focus on providing spatially specific estimates across the post-natal lifespan which provides fine-grained anatomical estimates of deviation that may be valuable for understanding the biological basis for mental disorders where individual patterns are widespread (e.g., not all individuals deviate in the same regions).

We also identify limitations of this work. First, we view the word "normative" as problematic. This language implies that there are normal and abnormal brains, a potentially problematic assumption. As indicated in Figure 2, there is considerable individual variability and heterogeneity among trajectories. We encourage the use of the phrase 'reference cohort' over 'normative model'. Second, to provide coverage of the lifespan the curated dataset is based on aggregating existing data, meaning there is unavoidable sampling bias. Race, education, and socioeconomic variables were not fully available for all included datasets, however, given that data were compiled from research studies, they are likely samples drawn predominantly from Western, Educated, Industrialized, Rich, and Democratic (WEIRD) societies (Henrich et al. (2010)) and future work should account for these factors. By sampling both healthy population samples and case-control studies, we achieve a reasonable estimate of variation across individuals, however, downstream analyses should consider the nature of the reference cohort and whether it is appropriate for the target sample. Finally, although the models presented in this study are comprehensive, they are only the first step, and we will augment our repository with more diverse data, different features and modelling advances as these become available. 


\section{Methods and Materials}

Data from 82 sites were combined to create the initial full sample. These sites are described in detail in Supplemental Table 5, including the sample size, age (mean and standard deviation), and sex distribution of each site. Many sites were pulled from publicly available data sets including ABCD, ABIDE, ADHD200, CAMCAN, CMI-HBN, HCP-Aging, HCP-Development, HCP-Early Psychosis, HCP-Young Adult, IXI, NKI-RS, Oasis, OpenNeuro, PNC, SRPBS, and UK Biobank. Other included data come from studies conducted at the University of Michigan (Duval et al. (2018); Rutherford et al. (2020); Tomlinson et al. (2020); Tso et al. (2021); Weigard et al. (2021); Zucker et al. (1996)), University of California Davis (Nordahl et al. (2020)), University of Oslo (Nesvåg et al. (2017)), King's College London (Green et al. (2012); Lythe et al. (2015)), and Amsterdam University Medical Center (Mocking et al. (2016)). Full details regarding sample characteristics, diagnostic procedures and acquisition protocols can be found in the publications associated with each of the studies. Equal sized training and testing data sets (split half) were created using scikit-learn's train_test_split function, stratifying on the site variable. It is important to stratify based on site, not only study (Bethlehem et al. (2021)), as many of the public studies (i.e., ABCD) include several sites, thus modeling study does not adequately address MRI scanner confounds.

The clinical validation sample consisted of a subset of the full data set (described in detail in Figure 2A and Supplemental Table 3). Studies (sites) contributing clinical data included: Autism Brain Imaging Database Exchange (ABIDE GU, KKI, NYU, USM), ADHD200 (KKI, NYU), CNP, SRPBS (CIN, COI, KTT, KUT, HKH, HRC, HUH, SWA, UTO), Delta (AmsterdamUMC), Human Connectome Project Early Psychosis (HCP-EP BWH, IU, McL, MGH), KCL, University of Michigan Schizophrenia Gaze Processing (UMich_SZG), and TOP (University of Oslo).

In addition to the sample-specific inclusion criteria, inclusion criteria for the full sample was based on participants having basic demographic information (age and sex), a T1-weighted MRI volume, and Freesurfer output directories that include summary files which represent left and right hemisphere cortical thickness values of the Destrieux parcellation and subcortical volumetric values (aseg.stats, Ih.aparc.a2009s.stats, rh.aparc.a2009s.stats). Freesurfer image analysis suite (version 6.0) was used for cortical reconstruction and volumetric segmentation for all studies. The technical details of these procedures are described in prior publications (Dale et al. (1999); Fischl and Dale (2000); Fischl et al. (2002)). UK Biobank was the only study for which Freesurfer was not run by the authors. Freesurfer functions aparcstats2table and asegstats2table were run to extract cortical thickness from the Destrieux parcellation (Destrieux et al. (2010)) and subcortical volume for all participants into CSV files. These files were inner merged with the demographic files, using Pandas, and NaN rows were dropped.

Quality control (QC) is an important consideration for large samples and is an active research area (Alfaro-Almagro et al. (2018); Klapwijk et al. (2019); Rosen et al. (2018)). We consider manual quality checking of images both prior to and after preprocessing to be the gold standard. However, this is labor intensive and prohibitive for very large samples. Therefore, in this work we adopt a pragmatic and multi-pronged approach to QC. First, a subset of the full data set underwent manual quality checking (mQC, described in Supplemental Table 4) by author S.R. using Papaya, a JavaScript based image viewer. Each subject's T1w volume was viewed in 3D volumetric space, with the Freesurfer brain.finalsurfs file as an overlay, to check for obvious quality issues such as excessive motion, ghosting or ringing artifacts. Example scripts used for quality checking can be found on GitHub. The ABCD study data distributes a variable (freesqc01.txt; fsqc_qc==1/0) that represents manual quality checking (pass/fail) of the T1w volume and Freesurfer data, thus this data set was added into our manual quality checked data set bringing the sample size to 24,354 individuals passing manual quality checks. Although this has a reduced sample, we consider this to be a gold standard sample in that every single scan has been checked manually. All inferences reported in this manuscript were validated against this sample. Second, for the full sample, we adopted an automated QC procedure that quantifies image quality based on the Freesurfer Euler 
Characteristic (EC), which has been shown to be an excellent proxy for manual labelling of scan quality (Monereo-Sánchez et al. (2021); Rosen et al. (2018)) and is the most important feature in automated scan quality classifiers (Klapwijk et al. (2019)). Since the distribution of the EC varies across sites, we adopt a simple approach that involves scaling and centering the distribution over the EC across sites and removing samples in the tail of the distribution (see (Kia et al. (2021)) for details).

Normative modeling was run using python 3.8 and the PCNtoolkit package (version 0.20). Bayesian Linear Regression (BLR) with likelihood warping was used to predict cortical thickness and subcortical volume from a vector of covariates (age, sex, site). For a complete mathematical description and explanation of this implementation see (Fraza et al. (2021)). Briefly, for each brain region of interest (cortical thickness or subcortical volume), y is predicted as:

$$
y=\omega^{\top} \varphi(x)+\epsilon
$$

Where $\omega^{\top}$ is the estimated weight vector, $\varphi(x)$ is a basis expansion of the of covariate vector $x$, consisting of a B-spline basis expansion (cubic spline with 5 evenly spaced knots) to model nonlinear effects of age, and $\epsilon=\eta(\theta, \beta)$ a Gaussian noise distribution with mean zero and noise precision term $\beta$ (the inverse variance). A likelihood warping approach (Rios and Tobar (2019); Snelson et al. (2003)) was used to model non-Gaussian effects. This involves applying a bijective nonlinear warping function to the non-Gaussian response variables to map them to a Gaussian latent space where inference can be performed in closed form. We employed a 'sinarcsinsh' warping function, which is equivalent to the SHASH distribution commonly used in the generalized additive modeling literature (Jones and Pewsey (2009)) and which we have found to perform well in prior work (Dinga et al. (2021); Fraza et al. (2021)). Site variation was modeled using fixed effects, which we have shown in prior work provides relatively good performance (Kia et al. (2021)), although random effects for site may provide additional flexibility at higher computational cost. A fast numerical optimization algorithm was used to optimize hyperparameters (L-BFGS). Computational complexity of hyperparameter optimization was controlled by minimizing the negative log likelihood. Deviation scores (Z-scores) are calculated for the $n_{t_{h}}$ subject, and $d_{t_{h}}$ brain area, in the test set as:

$$
Z_{n_{d}}=\frac{y_{n_{d}}-\hat{y_{n_{d}}}}{\sqrt{\left(\theta_{d}\right)^{2}+\left(\theta_{*_{d}}\right)^{2}}}
$$

Where $y_{n_{d}}$ is the true response, $\hat{y_{n_{d}}}$ is the predicted mean, $\theta_{d}^{2}$ is the estimated noise variance (reflecting uncertainty in the data), and $\theta_{*_{d}}^{2}$ is the variance attributed to modeling uncertainty. Model fit for each brain region was evaluated by calculating the explained variance (which measures central tendency), the mean squared log-loss (MSLL, central tendency and variance) plus skew and kurtosis of the deviation scores (equation 2) which measures how well the shape of the regression function matches the data (Dinga et al. (2021)). Note that for all models, we report out of sample metrics (Figure 3, Supplementary Table 5, Supplementary Table 6, Supplementary Table 7, and Supplementary Table 8).

To provide a summary of individual variation within each clinical group, deviation scores were summarized for each clinical group (Figure 2B-C) by first separating them into positive and negative deviations, counting how many subjects had an extreme deviation (positive extreme deviation defined as $Z>2$, negative extreme deviation as $Z<-2$ ) at a given ROI, and then dividing by the group size to show the percentage of individuals with extreme deviations at that brain area. Controls from the same sites as the patient groups were summarized in the same manner for comparison. We also performed classical case vs. control group difference testing on the true data and on the deviation scores (Figure 2D) and thresholded results at a Benjamini-Hochberg false discovery rate (FDR) of $p<0.05$. Note that in both cases, we directly contrast each patient group to their matched controls to avoid nuisance variation confounding any reported effects (e.g., sampling characteristics, demographic differences). 
All pretrained models and code are shared online with straightforward directions for transferring to new sites. Given a new set of data (e.g., sites not present in the training set), this is done by first applying the warp parameters estimating on the training data to the new dataset, adjusting the mean and variance in the latent Gaussian space, then (if necessary) warping the adjusted data back to the original space, which is similar to the approach outlined in (Dinga et al. (2021)). Note that to remain unbiased, this should be done on a held-out calibration dataset. To illustrate this procedure, we apply this approach to predicting a subset of sites in the 1000 functional connectomes project (Biswal et al. (2010)) that were not used during the model estimation step. These results are reported in Supplemental Figure 4 (bottom row). We also distribute scripts for this purpose in the GitHub Repository associated with this manuscript. Furthermore, to promote the use of these models and remove barriers to using them, we have set up access to the pretrained models and code for transferring to users' own data, using Google Colab, a free, cloud-based platform for running python notebooks. This eliminates the need to install python/manage package versions and only requires users to have a personal computer with stable internet connection.

\section{Acknowledgments}

This research was supported by grants from the European Research Council (ERC, grant "MENTALPRECISION" 10100118 and "BRAINMINT" 802998), the Wellcome Trust under an Innovator award ("BRAINCHART", 215698/Z/19/Z) and a Strategic Award (098369/Z/12/Z), the Dutch Organisation for Scientific Research (VIDI grant 016.156.415) the Research Council of Norway (223273, 249795, 298646, 300768, 276082), the South-Eastern Norway Regional Health Authority $(2014097,2015073$, 2016083, 2019101), the KG Jebsen Stiftelsen, an Autism Center of Excellence grant awarded by the National Institute of Child Health and Development (NICHD) (P50 HD093079) as well as the National Institute of Mental Health (R01 MH104438, R01MH103371). TW also gratefully acknowledges the Niels Stensen Fellowship as well as the European Union's Horizon 2020 research and innovation programme under the Marie Sklodowska-Curie Grant agreement No. 895011. RZ was funded by Medical Research Council grant (G0902304). IFT was funded by National Institute of Mental Health K23MH108823. SC was funded by National Institute on Deafness and other Communication Disorders (NIDCD/NIH) grant R01DC011277. CS was funded by the National Institute of Mental Health R01MH107741. MTwiNS was supported by the National Institute of Mental Health and the Office of the Director National Institute of Health, under Award Number UG3MH114249 and the Eunice Kennedy Shriver National Institute of Child Health \& Human Development of the National Institutes of Health under Award Number R01 HD093334 to SAB and LWH. RJTM was funded by an ABC Talent Grant. The ABCD Study is supported by the National Institutes of Health (NIH) award numbers U01DA041022, U01DA041028, U01DA041048, U01DA041089, U01DA041106, U01DA041117, U01DA041120, U01DA041134, U01DA041148, U01DA041156, U01DA041174, U24DA041123, and U24DA041147.

\section{Conflicts of Interest}

CFB is director and shareholder of SBGNeuro Ltd. OAA is a consultant for HealthLytix and received speaker's honorarium from Lundbeck and Sunovion. HGR received speaker's honorarium from Lundbeck and Janssen. The other authors report no conflicts of interest.

\section{References}

Alfaro-Almagro F, Jenkinson M, Bangerter NK, Andersson JLR, Griffanti L, Douaud G, Sotiropoulos SN, Jbabdi S, Hernandez-Fernandez M, Vallee E, Vidaurre D, Webster M, McCarthy P, Rorden C, Daducci A, Alexander DC, Zhang H, Dragonu I, Matthews PM, Miller KL, et al. Image processing and Quality Control for the first 10,000 brain imaging datasets from UK Biobank. Neurolmage. 2018 Feb; 166:400-424. https://linkinghub.elsevier. com/retrieve/pii/S1053811917308613, doi: 10.1016/j.neuroimage.2017.10.034.

Bayer JMM, Dinga R, Kia SM, Kottaram AR, Wolfers T, Lv J, Zalesky A, Schmaal L, Marquand A. Accommodating site variation in neuroimaging data using normative and hierarchical Bayesian models. 
bioRxiv. 2021 May; p. 2021.02.09.430363. https://www.biorxiv.org/content/10.1101/2021.02.09.430363v2, doi: 10.1101/2021.02.09.430363, publisher: Cold Spring Harbor Laboratory Section: Confirmatory Results.

Bethlehem R, Seidlitz J, White SR, Vogel JW, Anderson KM, Adamson C, Adler S, Alexopoulos GS, Anagnostou E, Areces-Gonzalez A, Astle DE, Auyeung B, Ayub M, Ball G, Baron-Cohen S, Beare R, Bedford SA, Benegal $\mathrm{V}$, Beyer F, Bae JB, et al. Brain charts for the human lifespan. bioRxiv. 2021 Jun; p. 2021.06.08.447489. https://www.biorxiv.org/content/10.1101/2021.06.08.447489v1, doi: 10.1101/2021.06.08.447489.

Bethlehem R, Seidlitz J, Romero-Garcia R, Trakoshis S, Dumas G, Lombardo MV. A normative modelling approach reveals age-atypical cortical thickness in a subgroup of males with autism spectrum disorder. Communications Biology. 2020 Sep; 3(1):486. doi: 10.1038/s42003-020-01212-9.

Biswal BB, Mennes M, Zuo XN, Gohel S, Kelly C, Smith SM, Beckmann CF, Adelstein JS, Buckner RL, Colcombe S, Dogonowski AM, Ernst M, Fair D, Hampson M, Hoptman MJ, Hyde JS, Kiviniemi VJ, Kotter R, Li SJ, Lin CP, et al. Toward discovery science of human brain function. Proceedings of the National Academy of Sciences. 2010 Mar; 107(10):4734-4739. http://www.pnas.org/cgi/doi/10.1073/pnas.0911855107, doi: $10.1073 /$ pnas.0911855107.

Cole TJ. The development of growth references and growth charts. Annals of Human Biology. 2012 Sep; 39(5):382-394. doi: 10.3109/03014460.2012.694475.

Dale AM, Fischl B, Sereno MI. Cortical surface-based analysis. I. Segmentation and surface reconstruction. Neuroimage. 1999 Feb; 9(2):179-194. http://dx.doi.org/10.1006/nimg.1998.0395, doi: 10.1006/nimg.1998.0395.

Destrieux C, Fischl B, Dale A, Halgren E. Automatic parcellation of human cortical gyri and sulci using standard anatomical nomenclature. Neurolmage. 2010 Oct; 53(1):1-15. doi: 10.1016/j.neuroimage.2010.06.010.

Dimitrova R, Pietsch M, Christiaens D, Ciarrusta J, Wolfers T, Batalle D, Hughes E, Hutter J, Cordero-Grande L, Price AN, Chew A, Falconer S, Vecchiato K, Steinweg JK, Carney O, Rutherford MA, Tournier JD, Counsell SJ, Marquand AF, Rueckert D, et al. Heterogeneity in Brain Microstructural Development Following Preterm Birth. Cerebral Cortex (New York, NY: 1991). 2020 Jul; 30(9):4800-4810. doi: 10.1093/cercor/bhaa069.

Dinga R, Fraza CJ, Bayer JMM, Kia SM, Beckmann CF, Marquand AF. Normative modeling of neuroimaging data using generalized additive models of location scale and shape. Neuroscience; 2021.

Ducharme S, Albaugh MD, Nguyen TV, Hudziak JJ, Mateos-Pérez JM, Labbe A, Evans AC, Karama S, Brain Development Cooperative Group. Trajectories of cortical thickness maturation in normal brain development-The importance of quality control procedures. Neurolmage. 2016 Jan; 125:267-279. doi: 10.1016/j.neuroimage.2015.10.010.

Duval ER, Joshi SA, Block SR, Abelson JL, Liberzon I. Insula Activation is Modulated by Attention Shifting in Social Anxiety Disorder. Journal of anxiety disorders. 2018 May; 56:56-62. https://www.ncbi.nlm.nih.gov/ pmc/articles/PMC5985215/, doi: 10.1016/j.janxdis.2018.04.004.

Fischl B, Dale AM. Measuring the thickness of the human cerebral cortex from magnetic resonance images. Proc Natl Acad Sci U S A. 2000 Sep; 97(20):11050-11055. http://dx.doi.org/10.1073/pnas.200033797, doi: 10.1073/pnas.200033797.

FischI B, Salat DH, Busa E, Albert M, Dieterich M, Haselgrove C, van der Kouwe A, Killiany R, Kennedy D, Klaveness S, Montillo A, Makris N, Rosen B, Dale AM. Whole Brain Segmentation. Neuron. 2002; 33(3):341-355. http: //dx.doi.org/10.1016/s0896-6273(02)00569-x, doi: 10.1016/s0896-6273(02)00569-x.

Fraza CJ, Dinga R, Beckmann CF, Marquand AF. Warped Bayesian Linear Regression for Normative Modelling of Big Data. bioRxiv. 2021 Apr; p. 2021.04.05.438429. https://www.biorxiv.org/content/10.1101/2021.04.05. 438429v1, doi: 10.1101/2021.04.05.438429.

Gogtay N, Giedd JN, Lusk L, Hayashi KM, Greenstein D, Vaituzis AC, Nugent TF, Herman DH, Clasen LS, Toga AW, Rapoport JL, Thompson PM. Dynamic mapping of human cortical development during childhood through early adulthood. Proceedings of the National Academy of Sciences. 2004 May; 101(21):8174-8179.

Green S, Lambon Ralph MA, Moll J, Deakin JFW, Zahn R. Guilt-Selective Functional Disconnection of Anterior Temporal and Subgenual Cortices in Major Depressive Disorder. Archives of General Psychiatry. 2012 Oct; 69(10):1014-1021. https://doi.org/10.1001/archgenpsychiatry.2012.135, doi: 10.1001/archgenpsychiatry.2012.135. 
Henrich J, Heine SJ, Norenzayan A. The weirdest people in the world? Behavioral and Brain Sciences. 2010 Jun; 33(2-3):61-83. https://www.cambridge.org/core/journals/behavioral-and-brain-sciences/article/abs/ weirdest-people-in-the-world/BF84F7517D56AFF7B7EB58411A554C17, doi: 10.1017/S0140525X0999152X, publisher: Cambridge University Press.

Insel TR. Mental disorders in childhood: shifting the focus from behavioral symptoms to neurodevelopmental trajectories. JAMA. 2014 May; 311(17):1727-1728. doi: 10.1001/jama.2014.1193.

Jack CR, Knopman DS, Jagust WJ, Shaw LM, Aisen PS, Weiner MW, Petersen RC, Trojanowski JQ. Hypothetical model of dynamic biomarkers of the Alzheimer's pathological cascade. The Lancet Neurology. 2010 Jan; 9(1):119-128. doi: 10.1016/S1474-4422(09)70299-6.

Jones MC, Pewsey A. Sinh-arcsinh distributions. Biometrika. 2009; 96(4):761-780. https://www.jstor.org/stable/ 27798865.

Karas GB, Scheltens P, Rombouts SaRB, Visser PJ, van Schijndel RA, Fox NC, Barkhof F. Global and local gray matter loss in mild cognitive impairment and Alzheimer's disease. Neurolmage. 2004 Oct; 23(2):708-716. doi: 10.1016/j.neuroimage.2004.07.006.

Kia SM, Huijsdens H, Rutherford S, Dinga R, Wolfers T, Mennes M, Andreassen OA, Westlye LT, Beckmann CF, Marquand AF. Federated Multi-Site Normative Modeling using Hierarchical Bayesian Regression. bioRxiv. 2021 May; p. 2021.05.28.446120. https://www. biorxiv.org/content/10.1101/2021.05.28.446120v1, doi: 10.1101/2021.05.28.446120.

Klapwijk ET, van de Kamp F, van der Meulen M, Peters S, Wierenga LM. Qoala-T: A supervised-learning tool for quality control of FreeSurfer segmented MRI data. Neurolmage. 2019 Apr; 189:116-129. doi: 10.1016/j.neuroimage.2019.01.014.

Lasagna CA, McLaughlin MM, Deng WY, Whiting EL, Tso IF. Deconstructing eye contact perception: Measuring perceptual precision and self-referential tendency using an online psychophysical eye contact detection task. PLOS ONE. 2020 Mar; 15(3):e0230258. https://journals.plos.org/plosone/article?id=10.1371/journal. pone. 0230258, doi: 10.1371/journal.pone.0230258, publisher: Public Library of Science.

Lythe KE, Moll J, Gethin JA, Workman Cl, Green S, Lambon Ralph MA, Deakin JFW, Zahn R. Self-blame-Selective Hyperconnectivity Between Anterior Temporal and Subgenual Cortices and Prediction of Recurrent Depressive Episodes. JAMA Psychiatry. 2015 Nov; 72(11):1119-1126. https://doi.org/10.1001/jamapsychiatry. 2015 1813, doi: 10.1001/jamapsychiatry.2015.1813.

Marquand AF, Kia SM, Zabihi M, Wolfers T, Buitelaar JK, Beckmann CF. Conceptualizing mental disorders as deviations from normative functioning. Molecular Psychiatry. 2019 Oct; 24(10):1415-1424. doi: 10.1038/s41380-019-0441-1.

Marquand AF, Rezek I, Buitelaar J, Beckmann CF. Understanding Heterogeneity in Clinical Cohorts Using Normative Models: Beyond Case-Control Studies. Biological Psychiatry. 2016 Oct; 80(7):552-561. doi: 10.1016/j.biopsych.2015.12.023.

Lever-van Milligen BA, Verhoeven JE, Schmaal L, van Velzen LS, Révész D, Black CN, Han LKM, Horsfall M, Batelaan NM, van Balkom AJLM, van Schaik DJF, van Oppen P, Penninx BWJH. The impact of depression and anxiety treatment on biological aging and metabolic stress: study protocol of the Mood treatment with antidepressants or running (MOTAR) study. BMC Psychiatry. 2019 Dec; 19(1):425. https://doi.org/10.1186/ s12888-019-2404-0, doi: 10.1186/s12888-019-2404-0.

Mocking RJT, Figueroa CA, Rive MM, Geugies H, Servaas MN, Assies J, Koeter MWJ, Vaz FM, Wichers M, van Straalen JP, de Raedt R, Bockting CLH, Harmer CJ, Schene AH, Ruhé HG. Vulnerability for new episodes in recurrent major depressive disorder: protocol for the longitudinal DELTA-neuroimaging cohort study. BMJ open. 2016 Mar; 6(3):e009510. doi: 10.1136/bmjopen-2015-009510.

Monereo-Sánchez J, de Jong JJA, Drenthen GS, Beran M, Backes WH, Stehouwer CDA, Schram MT, Linden DEJ, Jansen JFA. Quality control strategies for brain MRI segmentation and parcellation: Practical approaches and recommendations - insights from the Maastricht study. Neurolmage. 2021 Aug; 237:118174. doi: 10.1016/j.neuroimage.2021.118174.

Nesvåg R, Jönsson EG, Bakken IJ, Knudsen GP, Bjella TD, Reichborn-Kjennerud T, Melle I, Andreassen OA. The quality of severe mental disorder diagnoses in a national health registry as compared to research diagnoses based on structured interview. BMC Psychiatry. 2017 Mar; 17(1):93. https://doi.org/10.1186/ s12888-017-1256-8, doi: 10.1186/s12888-017-1256-8. 
NordahI CW, losif AM, Young GS, Hechtman A, Heath B, Lee JK, Libero L, Reinhardt VP, Winder-Patel B, Amaral DG, Rogers S, Solomon M, Ozonoff S. High Psychopathology Subgroup in Young Children With Autism: Associations With Biological Sex and Amygdala Volume. Journal of the American Academy of Child \& Adolescent Psychiatry. 2020 Dec; 59(12):1353-1363.e2. https://linkinghub.elsevier.com/retrieve/pii/S0890856720300186, doi: 10.1016/j.jaac.2019.11.022.

Rios G, Tobar F. Compositionally-warped Gaussian processes. Neural Networks. 2019 Oct; 118:235-246. https: //linkinghub.elsevier.com/retrieve/pii/S0893608019301856, doi: 10.1016/j.neunet.2019.06.012.

Rosen AFG, Roalf DR, Ruparel K, Blake J, Seelaus K, Villa LP, Ciric R, Cook PA, Davatzikos C, Elliott MA, Garcia de La Garza A, Gennatas ED, Quarmley M, Schmitt JE, Shinohara RT, Tisdall MD, Craddock RC, Gur RE, Gur RC, Satterthwaite TD. Quantitative assessment of structural image quality. Neurolmage. 2018 Apr; 169:407-418. doi: 10.1016/j.neuroimage.2017.12.059.

Rutherford S, Angstadt M, Sripada C, Chang SE. Leveraging big data for classification of children who stutter from fluent peers. bioRxiv. 2020 Oct; p. 2020.10.28.359711. https://www. biorxiv.org/content/10.1101/2020. 10.28.359711v1, doi: 10.1101/2020.10.28.359711, publisher: Cold Spring Harbor Laboratory Section: New Results.

Snelson E, Rasmussen CE, Ghahramani Z. Warped Gaussian processes. In: Proceedings of the 16th International Conference on Neural Information Processing Systems NIPS'03, Whistler, British Columbia, Canada: MIT Press; 2003. p. 337-344.

Snoek L, van der Miesen MM, Beemsterboer T, van der Leij A, Eigenhuis A, Steven Scholte H. The Amsterdam Open MRI Collection, a set of multimodal MRI datasets for individual difference analyses. Scientific Data. 2021 Mar; 8:85. https://www.ncbi.nlm.nih.gov/pmc/articles/PMC7979787/, doi: 10.1038/s41597-021-00870-6.

Tamnes CK, Østby Y, Fjell AM, Westlye LT, Due-Tønnessen P, Walhovd KB. Brain Maturation in Adolescence and Young Adulthood: Regional Age-Related Changes in Cortical Thickness and White Matter Volume and Microstructure. Cerebral Cortex. 2010 Mar; 20(3):534-548. https://doi.org/10.1093/cercor/bhp118, doi: 10.1093/cercor/bhp118.

Tomlinson RC, Burt SA, Waller R, Jonides J, Miller AL, Gearhardt AN, Peltier SJ, Klump KL, Lumeng JC, Hyde LW. Neighborhood poverty predicts altered neural and behavioral response inhibition. Neurolmage. 2020 Apr; 209:116536. https://www.sciencedirect.com/science/article/pii/S1053811920300239, doi: 10.1016/j.neuroimage.2020.116536.

Tso IF, Angstadt M, Rutherford S, Peltier S, Diwadkar VA, Taylor SF. Dynamic causal modeling of eye gaze processing in schizophrenia. Schizophrenia Research. 2021 Mar; 229:112-121. https://www.sciencedirect. com/science/article/pii/S092099642030551X, doi: 10.1016/j.schres.2020.11.012.

Weigard AS, Brislin SJ, Cope LM, Hardee JE, Martz ME, Ly A, Zucker RA, Sripada C, Heitzeg MM. Evidence accumulation and associated error-related brain activity as computationally-informed prospective predictors of substance use in emerging adulthood. Psychopharmacology. 2021 Jun; https://doi.org/10.1007/ s00213-021-05885-w, doi: 10.1007/s00213-021-05885-w.

Wolfers T, Arenas AL, Onnink AMH, Dammers J, Hoogman M, Zwiers MP, Buitelaar JK, Franke B, Marquand AF, Beckmann CF. Refinement by integration: aggregated effects of multimodal imaging markers on adult ADHD. Journal of Psychiatry \& Neuroscience : JPN. 2017 Nov; 42(6):386-394. https://www.ncbi.nlm.nih.gov/ pmc/articles/PMC5662460/, doi: 10.1503/jpn.160240.

Wolfers T, Beckmann CF, Hoogman M, Buitelaar JK, Franke B, Marquand AF. Individual differences v. the average patient: mapping the heterogeneity in ADHD using normative models. Psychological Medicine. 2020 Jan; 50(2):314-323. doi: 10.1017/S0033291719000084.

Wolfers T, Doan NT, Kaufmann T, Alnæs D, Moberget T, Agartz I, Buitelaar JK, Ueland T, Melle I, Franke B, Andreassen OA, Beckmann CF, Westlye LT, Marquand AF. Mapping the Heterogeneous Phenotype of Schizophrenia and Bipolar Disorder Using Normative Models. JAMA Psychiatry. 2018 Nov; 75(11):1146-1155. https://doi.org/10.1001/jamapsychiatry.2018.2467, doi: 10.1001/jamapsychiatry.2018.2467.

Wolfers T, Rokicki J, Alnaes D, Berthet P, Agartz I, Kia SM, Kaufmann T, Zabihi M, Moberget T, Melle I, Beckmann CF, Andreassen OA, Marquand AF, Westlye LT. Replicating extensive brain structural heterogeneity in individuals with schizophrenia and bipolar disorder. Human Brain Mapping. 2021 Jun; 42(8):2546-2555. doi: 10.1002/hbm.25386. 
bioRxiv preprint doi: https://doi.org/10.1101/2021.08.08.455487; this version posted August 9, 2021. The copyright holder for this preprint (which was not certified by peer review) is the author/funder, who has granted bioRxiv a license to display the preprint in perpetuity. It is made available under aCC-BY 4.0 International license.

Yao B, Mueller SA, Grove TB, McLaughlin M, Thakkar K, Ellingrod V, McInnis MG, Taylor SF, Deldin PJ, Tso IF. Eye Gaze Perception in Bipolar Disorder: Self-referential Bias but Intact Perceptual Sensitivity. Bipolar disorders. 2018 Feb; 20(1):60-69. https://www.ncbi.nlm.nih.gov/pmc/articles/PMC5807101/, doi: 10.1111/bdi.12564.

Zabihi M, Floris DL, Kia SM, Wolfers T, Tillmann J, Arenas AL, Moessnang C, Banaschewski T, Holt R, Baron-Cohen S, Loth E, Charman T, Bourgeron T, Murphy D, Ecker C, Buitelaar JK, Beckmann CF, Marquand A, EU-AIMS LEAP Group. Fractionating autism based on neuroanatomical normative modeling. Translational Psychiatry. 2020 Nov; 10(1):384. doi: 10.1038/s41398-020-01057-0.

Zabihi M, Oldehinkel M, Wolfers T, Frouin V, Goyard D, Loth E, Charman T, Tillmann J, Banaschewski T, Dumas G, Holt R, Baron-Cohen S, Durston S, Bölte S, Murphy D, Ecker C, Buitelaar JK, Beckmann CF, Marquand AF. Dissecting the Heterogeneous Cortical Anatomy of Autism Spectrum Disorder Using Normative Models. Biological Psychiatry Cognitive Neuroscience and Neuroimaging. 2019 Jun; 4(6):567-578. doi: 10.1016/j.bpsc.2018.11.013.

Zucker RA, Ellis DA, Fitzgerald HE, Bingham CR, Sanford K. Other evidence for at least two alcoholisms II: Life course variation in antisociality and heterogeneity of alcoholic outcome. Development and Psychopathology. 1996; 8(4):831-848. http://www.cambridge.org/core/journals/development-and-psychopathology/article/ other-evidence-for-at-least-two-alcoholisms-ii-life-course-variation-in-antisociality-and-heterogeneity-of-alcoholic-outcome/ F477F2272522FCFB6F7A13011EB38BBB, doi: 10.1017/S0954579400007458, publisher: Cambridge University Press.

\section{Explained Variance in Test Sets}

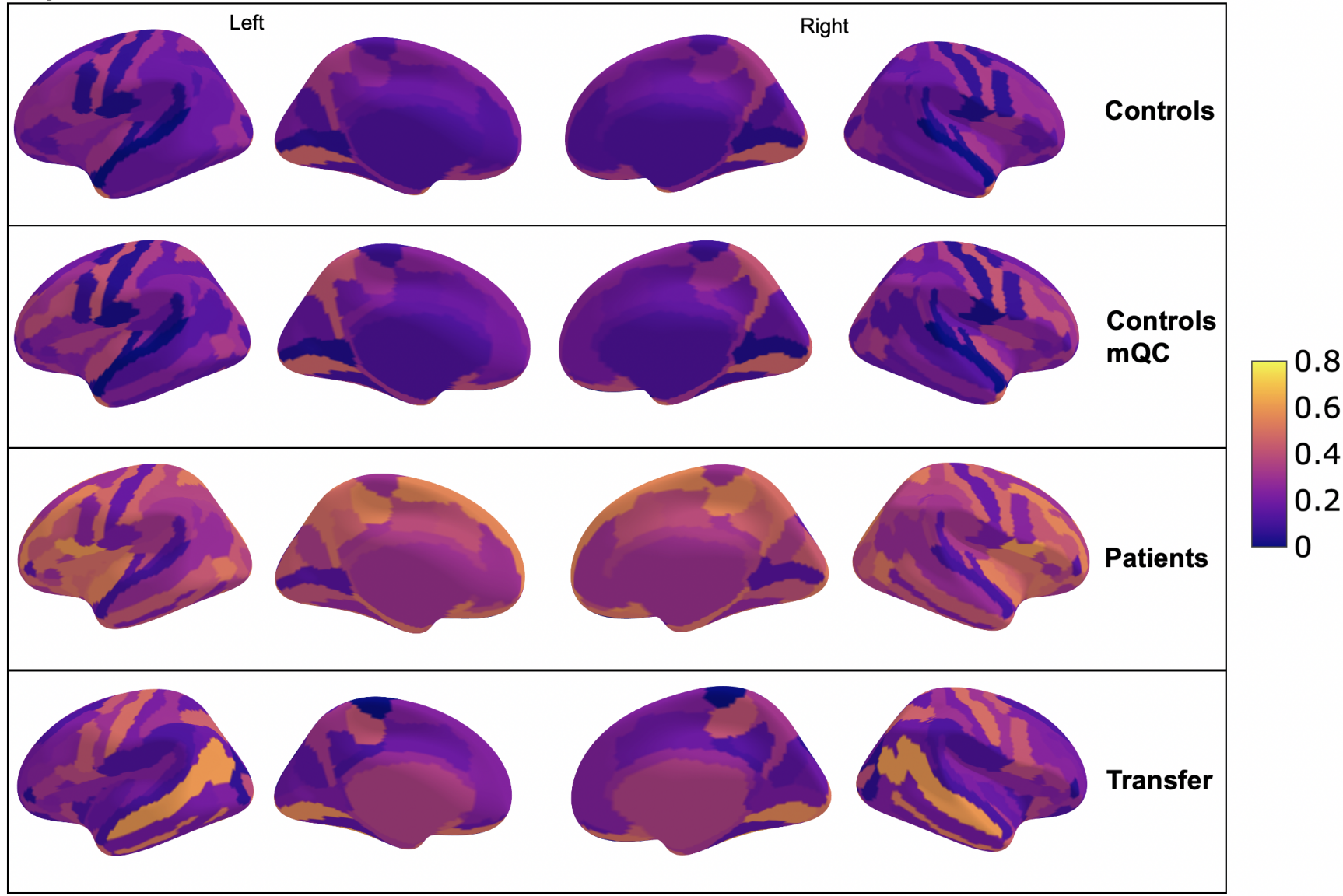

Appendix 0 Figure 4. Comparison of the explained variance in cortical thickness across the different test sets. The patterns appear to be robust and consistent across the different test sets. 
bioRxiv preprint doi: https://doi.org/10.1101/2021.08.08.455487; this version posted August 9,2021 . The copyright holder for this preprint (which was not certified by peer review) is the author/funder, who has granted bioRxiv a license to display the preprint in perpetuity. It is made available under aCC-BY 4.0 International license.

Appendix 0 Table 2. Full Sample Description, per site, in the train and test sets.

\begin{tabular}{|c|c|c|c|c|c|c|}
\hline Site & Train N & $\% \mathrm{~F} / \mathrm{M}$ & Age $(m, s . d)$ & Test N & $\% \mathrm{~F} / \mathrm{M}$ & Age $(m, s . d)$ \\
\hline ABCD_01 & 194 & $0.52,0.48$ & $9.95,0.62$ & 194 & $0.51,0.49$ & $9.85,0.63$ \\
\hline ABCD_02 & 271 & $0.47,0.53$ & $10.12,0.6$ & 271 & $0.46,0.54$ & $10.03,0.64$ \\
\hline ABCD_03 & 285 & $0.46,0.54$ & $9.86,0.62$ & 284 & $0.48,0.52$ & $9.9,0.62$ \\
\hline ABCD_04 & 315 & $0.47,0.53$ & $9.81,0.64$ & 316 & $0.5,0.5$ & $9.82,0.65$ \\
\hline ABCD_05 & 172 & $0.53,0.47$ & $9.9,0.65$ & 173 & $0.5,0.5$ & $9.89,0.62$ \\
\hline ABCD_06 & 282 & $0.5,0.5$ & $9.96,0.59$ & 282 & $0.51,0.49$ & $9.93,0.59$ \\
\hline ABCD_07 & 162 & $0.46,0.54$ & $9.87,0.63$ & 163 & $0.48,0.52$ & $9.87,0.62$ \\
\hline ABCD_08 & 168 & $0.42,0.58$ & $10,0.62$ & 168 & $0.54,0.46$ & $9.91,0.62$ \\
\hline ABCD_09 & 204 & $0.52,0.48$ & $9.95,0.63$ & 203 & $0.46,0.54$ & $9.98,0.59$ \\
\hline ABCD_10 & 287 & $0.47,0.53$ & $9.85,0.63$ & 288 & $0.5,0.5$ & $9.87,0.62$ \\
\hline ABCD_11 & 207 & $0.52,0.48$ & $9.84,0.62$ & 207 & $0.47,0.53$ & $9.79,0.64$ \\
\hline ABCD_12 & 81 & $0.41,0.59$ & $9.89,0.56$ & 80 & $0.55,0.45$ & $9.87,0.62$ \\
\hline ABCD_13 & 277 & $0.53,0.47$ & $9.81,0.58$ & 278 & $0.47,0.53$ & $9.82,0.61$ \\
\hline ABCD_14 & 292 & $0.45,0.55$ & $10.17,0.56$ & 291 & $0.47,0.53$ & $10.22,0.57$ \\
\hline ABCD_15 & 198 & $0.44,0.56$ & $9.87,0.59$ & 197 & $0.46,0.54$ & $9.94,0.62$ \\
\hline ABCD_16 & 460 & $0.45,0.55$ & $9.91,0.65$ & 461 & $0.45,0.55$ & $9.9,0.65$ \\
\hline ABCD_17 & 278 & $0.48,0.52$ & $9.79,0.61$ & 279 & $0.48,0.52$ & $9.84,0.64$ \\
\hline ABCD_18 & 171 & $0.48,0.52$ & $9.92,0.61$ & 170 & $0.46,0.54$ & $9.9,0.65$ \\
\hline ABCD_19 & 267 & $0.49,0.51$ & $10.04,0.55$ & 267 & $0.53,0.47$ & $10.08,0.54$ \\
\hline ABCD_20 & 320 & $0.51,0.49$ & $10.05,0.5$ & 320 & $0.49,0.51$ & $10.07,0.48$ \\
\hline ABCD_21 & 246 & $0.42,0.58$ & $9.92,0.65$ & 245 & $0.48,0.52$ & $9.91,0.6$ \\
\hline ABIDE_GU & 27 & $0.41,0.59$ & $10.57,1.68$ & 27 & $0.59,0.41$ & $10.29,1.75$ \\
\hline ABIDE_KKI & 93 & $0.34,0.66$ & $10.35,1.19$ & 94 & $0.35,0.65$ & $10.24,1.2$ \\
\hline ABIDE_NYU & 68 & $0.15,0.85$ & $14.35,6.01$ & 67 & $0.27,0.73$ & $14.47,6.62$ \\
\hline ABIDE_USM & 30 & $0.07,0.93$ & $23.12,6.14$ & 29 & $0.03,0.97$ & $20.98,9.03$ \\
\hline ADD200_KKI & 31 & $0.45,0.55$ & $10.23,1.28$ & 30 & $0.43,0.57$ & $10.27,1.29$ \\
\hline ADD200_NYU & 19 & $0.68,0.32$ & $10.04,2.2$ & 19 & $0.37,0.63$ & $10.38,1.6$ \\
\hline AOMIC_1000 & 464 & $0.51,0.49$ & $22.87,1.71$ & 464 & $0.53,0.47$ & $22.83,1.71$ \\
\hline AOMIC_PIPO2 & 104 & $0.59,0.41$ & $22.21,1.91$ & 105 & $0.56,0.44$ & $22.16,1.69$ \\
\hline ATV & 39 & $0.21,0.79$ & $22.59,1.96$ & 38 & $0.24,0.76$ & $22.76,2.02$ \\
\hline CAMCAN & 323 & $0.52,0.48$ & $55.11,19.37$ & 324 & $0.5,0.5$ & $53.28,17.7$ \\
\hline $\mathrm{CIN}$ & 33 & $0.33,0.67$ & $48.64,15.83$ & 33 & $0.33,0.67$ & $47.15,18.14$ \\
\hline CMI-HBN_CBIC & 99 & $0.35,0.65$ & $11.16,3.73$ & 100 & $0.38,0.62$ & $11.24,3.74$ \\
\hline CMI-HBN_RU & 188 & $0.3,0.7$ & $10.37,3.3$ & 188 & $0.36,0.64$ & $10.69,3.74$ \\
\hline CMI-HBN_SI & 53 & $0.32,0.68$ & $11.24,3.83$ & 53 & $0.4,0.6$ & $10.79,3.64$ \\
\hline CNP-35343.0 & 45 & $0.51,0.49$ & $31.91,8.39$ & 45 & $0.44,0.56$ & $31.98,9.48$ \\
\hline CNP-35426.0 & 10 & $0.6,0.4$ & $28.1,7.17$ & 10 & $0.5,0.5$ & $30.9,8.75$ \\
\hline $\mathrm{COI}$ & 62 & $0.63,0.37$ & $51.92,14.31$ & 62 & $0.63,0.37$ & $51.81,12.64$ \\
\hline delta & 24 & $0.42,0.58$ & $50.17,9.27$ & 25 & $0.32,0.68$ & $50.72,8.44$ \\
\hline ON_ds001734 & 54 & $0.52,0.48$ & $25.43,3.75$ & 54 & $0.59,0.41$ & $25.67,3.45$ \\
\hline ON_ds002236 & 43 & $0.42,0.58$ & $10.99,1.75$ & 43 & $0.47,0.53$ & $11.99,2.21$ \\
\hline ON_ds002330 & 33 & $0.58,0.42$ & $26.52,4.15$ & 33 & $0.55,0.45$ & $26.73,4.52$ \\
\hline ON_ds002345 & 104 & $0.63,0.38$ & $21.61,4.12$ & 103 & $0.64,0.36$ & $21.79,5.26$ \\
\hline ON_ds002731 & 29 & $0.66,0.34$ & $21.21,1.57$ & 30 & $0.3,0.7$ & $21.3,1.34$ \\
\hline ON_ds002837 & 43 & $0.56,0.44$ & $27.23,10.63$ & 43 & $0.42,0.58$ & $26.23,9.55$ \\
\hline
\end{tabular}


bioRxiv preprint doi: https:/doi.org/10.1101/2021.08.08.455487; this version posted Auqust 9,2021 . The copyright holder for this preprint (which was not certified by peer review) is the author/funder, who has granted bioRxiv a license to display the preprint in perpetuity. It is made available under aCC-BY 4.0 International license.

Appendix 0 Table 2. Full Sample Description, per site, in the train and test sets.

\begin{tabular}{|c|c|c|c|c|c|c|}
\hline Site & Train N & $\% \mathrm{~F} / \mathrm{M}$ & Age $(m, s . d)$ & Test N & $\% \mathrm{~F} / \mathrm{M}$ & Age $(m, s . d)$ \\
\hline HCP_A_MGH & 85 & $0.53,0.47$ & $61.41,16.18$ & 86 & $0.48,0.52$ & $58.13,14.79$ \\
\hline HCP_A_UCLA & 62 & $0.58,0.42$ & $51.77,11.36$ & 62 & $0.56,0.44$ & $54.89,14.03$ \\
\hline HCP_A_UM & 102 & $0.66,0.34$ & $63.71,16.77$ & 102 & $0.52,0.48$ & $59.48,15.63$ \\
\hline HCP_A_WU & 89 & $0.64,0.36$ & $59.79,14.34$ & 89 & $0.62,0.38$ & $57.89,12.54$ \\
\hline HCP_D_MGH & 108 & $0.53,0.47$ & $14.4,3.94$ & 108 & $0.48,0.52$ & $13.17,3.72$ \\
\hline HCP_D_UCLA & 63 & $0.52,0.48$ & $14.3,3.63$ & 64 & $0.45,0.55$ & $13.98,4.04$ \\
\hline HCP_D_UM & 78 & $0.53,0.47$ & $13.71,3.69$ & 78 & $0.56,0.44$ & $12.82,3.55$ \\
\hline HCP_D_WU & 77 & $0.47,0.53$ & $14.21,4.25$ & 77 & $0.51,0.49$ & $13.73,3.46$ \\
\hline HCP_EP_BWH & 4 & $0.25,0.75$ & $21.92,2.07$ & 4 & $0.25,0.75$ & $24.27,4.28$ \\
\hline HCP_EP_IU & 12 & $0.42,0.58$ & $24.76,4.21$ & 13 & $0.46,0.54$ & $23.12,3.27$ \\
\hline HCP_EP_McL & 7 & $0.29,0.71$ & $26.49,4.29$ & 6 & $0.33,0.67$ & $23.6,2.33$ \\
\hline HCP_EP_MGH & 6 & $0.17,0.83$ & $26.89,4.1$ & 5 & $0.4,0.6$ & $28.48,5.97$ \\
\hline HCP_YA & 557 & $0.55,0.45$ & $28.76,3.73$ & 556 & $0.53,0.47$ & $28.85,3.66$ \\
\hline $\mathrm{HKH}$ & 15 & $0.47,0.53$ & $46.27,7.69$ & 14 & $0.71,0.29$ & $44.5,11.42$ \\
\hline HRC & 25 & $0.76,0.24$ & $45.88,12.74$ & 24 & $0.71,0.29$ & $37.33,8.7$ \\
\hline $\mathrm{HUH}$ & 33 & $0.55,0.45$ & $38.24,13.66$ & 34 & $0.59,0.41$ & $31.35,11.45$ \\
\hline IXI & 279 & $0.56,0.44$ & $47.9,16.57$ & 279 & 0.56 & 49.53, \\
\hline KCL & 20 & $0.65,0.35$ & $34.65,14.13$ & 21 & $0.57,0$ & $33.62,13.44$ \\
\hline KTT & 64 & $0.28,0.72$ & 30.77, 9.7 & 64 & $0.36,0.64$ & $31.3,8.88$ \\
\hline KUT & 79 & $0.39,0.61$ & $36.91,13.35$ & 80 & $0.44,0.56$ & $36.11,13.89$ \\
\hline NKI-RS & 241 & $0.6,0.4$ & $42.63,21.75$ & 241 & $0.27,0.73$ & $42.63,20.67$ \\
\hline Oasis2 & 93 & $0.66,0.34$ & $75.92,7.3$ & 92 & $1.77,-0.77$ & $77.86,8.79$ \\
\hline Oasis3 & 776 & $0.4,0.6$ & $69.41,9.01$ & 776 & $0.41,0.59$ & $70.16,9$ \\
\hline PNC & 689 & $0.52,0.48$ & $14.16,3.48$ & 689 & $0.01,0.99$ & $14.28,3.54$ \\
\hline SWA & 50 & $0.14,0.86$ & $27.34,6.77$ & 50 & $6.92,-5.92$ & $29.62,8.79$ \\
\hline SWU_SLIM_ses1 & 274 & $0.59,0.41$ & $20.07,1.3$ & 274 & $0.57,0.43$ & $20.08,1.25$ \\
\hline TOP & 146 & $0.45,0.55$ & $34.25,9.68$ & 146 & $0.47,0.53$ & $34.9,9.43$ \\
\hline UCDavis & 69 & $0.49,0.51$ & $3.16,0.57$ & 67 & $0.42,0.58$ & $3.09,0.55$ \\
\hline ukb-11025.0 & 12493 & $0.52,0.48$ & $63,7.51$ & 12493 & $0.52,0.48$ & $62.98,7.52$ \\
\hline ukb-11027.0 & 4986 & $0.55,0.45$ & $64.35,7.38$ & 4986 & $0.54,0.46$ & $64.44,7.47$ \\
\hline UMich_CWS & 14 & $0.57,0.43$ & $5.23,1.15$ & 15 & $0.6,0.4$ & $5.44,1.16$ \\
\hline UMich_IMPs & 107 & $0.55,0.45$ & $12.91,3.56$ & 107 & $0.55,0.45$ & $12.83,3.29$ \\
\hline UMich_MLS & 79 & $0.39,0.61$ & $19.94,1.52$ & 78 & $0.33,0.67$ & $20.14,1.5$ \\
\hline UMich_MTwins & 300 & $0.47,0.53$ & $14.28,1.97$ & 300 & $0.45,0.55$ & $14.28,2.13$ \\
\hline UMich_SAD & 57 & $0.4,0.6$ & $24.02,4.75$ & 57 & $0.35,0.65$ & $26.56,9.02$ \\
\hline UMich_SZG & 23 & $0.43,0.57$ & $32.09,11.09$ & 22 & $0.55,0.45$ & $31.64,8.63$ \\
\hline UTO & 101 & $0.56,0.44$ & $35.01,17.31$ & 101 & $0.49,0.51$ & $35.39,16.53$ \\
\hline
\end{tabular}

Appendix 0 Table 3. Clinical Sample Description

\begin{tabular}{lrll}
\hline Site & Patient N & \%F/M & Age $(\mathrm{m}, \mathrm{s.d})$ \\
\hline ABIDE_GU & 47 & $0.17,0.83$ & $10.94,1.53$ \\
ABIDE_KKI & 77 & $0.25,0.75$ & $10.23,1.5$ \\
ABIDE_NYU & 127 & $0.13,0.87$ & $12.83,6.86$ \\
ABIDE_USM & 74 & $0.03,0.97$ & $21.61,7.78$ \\
\hline \multicolumn{3}{c}{ Continued on next page }
\end{tabular}


Appendix 0 Table 3. Clinical Sample Description

\begin{tabular}{lrll}
\hline Site & Patient N & $\% \mathrm{~F} / \mathrm{M}$ & Age $(\mathrm{m}, \mathrm{s} . \mathrm{d})$ \\
\hline ADD200_KKI & 22 & $0.45,0.55$ & $10.22,1.56$ \\
ADD200_NYU & 52 & $0.27,0.73$ & $10.05,1.67$ \\
CNP-35343.0 & 63 & $0.48,0.52$ & $35.33,9.75$ \\
CNP-35426.0 & 59 & $0.25,0.75$ & $34.63,9.35$ \\
COI & 69 & $0.58,0.42$ & $45.07,12.62$ \\
delta & 111 & $0.43,0.57$ & $45.23,13.18$ \\
HCP_EP_BWH & 23 & $0.35,0.65$ & $22.39,4.26$ \\
HCP_EP_IU & 59 & $0.37,0.63$ & $22.97,3.84$ \\
HCP_EP_MCL & 31 & $0.48,0.52$ & $23.56,3.46$ \\
HCP_EP_MGH & 10 & $0.3,0.7$ & $20.32,2.99$ \\
HKH & 33 & $0.39,0.61$ & $44.82,11.47$ \\
HRC & 16 & $0.63,0.38$ & $40.5,11.48$ \\
HUH & 57 & $0.44,0.56$ & $43.33,12.18$ \\
KCL & 104 & $0.72,0.28$ & $31.44,11.86$ \\
KTT & 47 & $0.45,0.55$ & $37.89,9.79$ \\
KUT & 61 & $0.49,0.51$ & $41.7,11.18$ \\
SWA & 134 & $0.14,0.86$ & $33.62,8.73$ \\
TOP & 531 & $0.48,0.52$ & $32.42,10.45$ \\
UMich_SZG & 70 & $0.51,0.49$ & $32.77,9.77$ \\
UTO & 108 & $0.36,0.64$ & $36.1,11.5$ \\
\hline
\end{tabular}

Appendix 0 Table 4. mQC Sample Description, per site, in the train and test sets.

\begin{tabular}{lrllrll}
\hline Site & Train N & \%F/M & Age $(\mathrm{m}, \mathrm{s} . \mathrm{d})$ & Test N & $\% \mathrm{~F} / \mathrm{M}$ & Age $(\mathrm{m}, \mathrm{s} . \mathrm{d})$ \\
\hline ABCD_01 & 180 & $0.53,0.47$ & $9.88,0.62$ & 179 & $0.47,0.53$ & $9.93,0.63$ \\
ABCD_02 & 267 & $0.47,0.53$ & $10.12,0.6$ & 266 & $0.45,0.55$ & $10.02,0.64$ \\
ABCD_03 & 282 & $0.49,0.51$ & $9.87,0.61$ & 282 & $0.45,0.55$ & $9.9,0.62$ \\
ABCD_04 & 275 & $0.48,0.52$ & $9.87,0.63$ & 276 & $0.5,0.5$ & $9.79,0.66$ \\
ABCD_05 & 169 & $0.51,0.49$ & $9.94,0.65$ & 170 & $0.52,0.48$ & $9.86,0.6$ \\
ABCD_06 & 280 & $0.5,0.5$ & $9.97,0.59$ & 279 & $0.51,0.49$ & $9.93,0.59$ \\
ABCD_07 & 160 & $0.43,0.57$ & $9.88,0.6$ & 160 & $0.51,0.49$ & $9.85,0.65$ \\
ABCD_08 & 132 & $0.42,0.58$ & $9.98,0.63$ & 131 & $0.52,0.48$ & $10.01,0.6$ \\
ABCD_09 & 197 & $0.5,0.5$ & $9.96,0.6$ & 197 & $0.5,0.5$ & $9.97,0.63$ \\
ABCD_10 & 248 & $0.46,0.54$ & $9.9,0.63$ & 249 & $0.51,0.49$ & $9.83,0.61$ \\
ABCD_11 & 203 & $0.44,0.56$ & $9.81,0.63$ & 203 & $0.55,0.45$ & $9.82,0.63$ \\
ABCD_12 & 79 & $0.48,0.52$ & $9.97,0.57$ & 79 & $0.48,0.52$ & $9.79,0.61$ \\
ABCD_13 & 240 & $0.5,0.5$ & $9.83,0.62$ & 240 & $0.51,0.49$ & $9.82,0.59$ \\
ABCD_14 & 285 & $0.41,0.59$ & $10.2,0.56$ & 285 & $0.51,0.49$ & $10.21,0.57$ \\
ABCD_15 & 188 & $0.49,0.51$ & $9.88,0.59$ & 188 & $0.41,0.59$ & $9.93,0.61$ \\
ABCD_16 & 459 & $0.43,0.57$ & $9.9,0.66$ & 459 & $0.47,0.51$ & $9.91,0.65$ \\
ABCD_17 & 264 & $0.51,0.49$ & $9.78,0.62$ & 265 & $0.47,0.53$ & $9.87,0.64$ \\
ABCD_18 & 139 & $0.43,0.57$ & $9.99,0.62$ & 139 & $0.48,0.52$ & $9.92,0.64$ \\
ABCD_19 & 254 & $0.5,0.5$ & $10.11,0.55$ & 254 & $0.52,0.48$ & $10.02,0.54$ \\
ABCD_20 & 314 & $0.51,0.49$ & $10.08,0.48$ & 314 & $0.49,0.51$ & $10.04,0.5$ \\
ABCD_21 & 239 & $0.47,0.53$ & $9.93,0.62$ & 239 & $0.44,0.56$ & $9.9,0.62$ \\
\hline
\end{tabular}

Continued on next page 
bioRxiv preprint doi: https://doi.org/10.1101/2021.08.08.455487; this version posted Auqust 9,2021 . The copyright holder for this preprint (which was not certified by peer review) is the author/funder, who has granted bioRxiv a license to display the preprint in perpetuity. It is made available under aCC-BY 4.0 International license.

Appendix 0 Table 4. mQC Sample Description, per site, in the train and test sets.

\begin{tabular}{|c|c|c|c|c|c|c|}
\hline Site & Train N & $\% \mathrm{~F} / \mathrm{M}$ & Age $(m, s . d)$ & Test $\mathrm{N}$ & $\% \mathrm{~F} / \mathrm{M}$ & Age $(m, s . d)$ \\
\hline CAMCAN & 306 & $0.49,0.51$ & $52.83,18.39$ & 307 & $0.53,0.53$ & $53.56,18.16$ \\
\hline CMI-HBN_RU & 170 & $0.35,0.65$ & $11.3,3.4$ & 170 & $0.38,0.62$ & $10.5,3.7$ \\
\hline CMI-HBN_SI & 141 & $0.41,0.59$ & $12.1,3.9$ & 141 & $0.47,0.53$ & $11.4,3.7$ \\
\hline CNP-35343.0 & 44 & $0.39,0.61$ & $33.43,9.5$ & 43 & $0.58,0.42$ & $30.53,8.26$ \\
\hline CNP-35426.0 & 10 & $0.7,0.3$ & $28.7,6.15$ & 9 & $0.44,0.56$ & $29.33,9.71$ \\
\hline delta & 24 & $0.42,0.58$ & $50.92,8.48$ & 23 & $0.3,0.7$ & $49.57,9.44$ \\
\hline ON_ds001734 & 54 & $0.57,0.43$ & $25.61,3.8$ & 54 & $0.54,0.46$ & $25.48,3.4$ \\
\hline ON_ds002236 & 37 & $0.46,0.54$ & $11.55,2.02$ & 37 & $0.51,0.49$ & $11.79,2.17$ \\
\hline ON_ds002330 & 33 & $0.52,0.48$ & $27.09,4.24$ & 33 & $0.61,0.39$ & $26.15,4.39$ \\
\hline ON_ds002345 & 104 & $0.66,0.34$ & $21.61,4.36$ & 103 & $0.6,0.5$ & $21.79,5.06$ \\
\hline ON_ds002731 & 29 & $0.48,0.52$ & $21.38,1.7$ & 30 & $0.47,0.53$ & $21.13,1.17$ \\
\hline ON_ds002837 & 43 & $0.53,0.47$ & $26.3,9.05$ & 43 & $0.44,0.56$ & $27.16,11.06$ \\
\hline HCP_A_MGH & 85 & $0.56,0.44$ & $60.03,15.91$ & 85 & $0.44,0.56$ & $59.02,14.68$ \\
\hline HCP_A_UCLA & 60 & $0.57,0.43$ & $55.35,13.24$ & 61 & $0.61,0.39$ & $50.91,11.6$ \\
\hline HCP_A_UM & 101 & $0.59,0.41$ & $61.78,16.25$ & 100 & $0.58,0.42$ & $60.44,15.59$ \\
\hline HCP_A_WU & 88 & $0.63,0.38$ & $58.93,13.48$ & 88 & $0.63,0.38$ & $58.25,13.25$ \\
\hline HCP_D_MGH & 106 & $0.52,0.48$ & $13.94,3.79$ & 106 & $0.49,0.51$ & $13.74,3.97$ \\
\hline HCP_D_UCLA & 63 & $0.46,0.54$ & $13.41,3.76$ & 62 & $0.5,0.5$ & $14.86,3.85$ \\
\hline HCP_D_UM & 78 & $0.6,0.4$ & $13.61,3.64$ & 78 & $0.49,0.51$ & $12.93,3.64$ \\
\hline HCP_D_WU & 76 & $0.43,0.57$ & $13.61,3.74$ & 75 & $0.53,0.47$ & $14.32,3.94$ \\
\hline $\mathrm{HCP}_{-} \mathrm{EP} \mathrm{P}_{-} \mathrm{BWH}$ & 15 & $0.33,0.67$ & $22.59,4$ & 16 & $0.31,0.69$ & $22.55,4.14$ \\
\hline HCP_EP_IU & 42 & $0.38,0.62$ & $23.12,4.02$ & 41 & $0.41,0.59$ & $23.43,3.68$ \\
\hline HCP_EP_McL & 22 & $0.32,0.68$ & $23.87,2.94$ & 22 & $0.14,0.36$ & $24.2,4.16$ \\
\hline HCP_EP_MGH & 10 & $0.3,0.7$ & $27.56,5.58$ & 11 & $1.09,0.91$ & $21.03,2.99$ \\
\hline $\mathrm{HCP}_{-} \mathrm{YA}^{-}$ & 556 & $0.54,0.46$ & $28.96,3.66$ & 556 & $0.55,0.45$ & $28.65,3.73$ \\
\hline IXI & 276 & $0.58,0.42$ & $48.7,16.25$ & 277 & $0.55,0.45$ & $48.76,16.73$ \\
\hline $\mathrm{KCL}$ & 20 & $0.8,0.2$ & $32.8,13.23$ & 20 & $0.45,0.55$ & $34.75,14.25$ \\
\hline NKI-RS & 229 & $0.66,0.34$ & $43.98,20.32$ & 228 & $0.63,0.37$ & $43.26,20.56$ \\
\hline Oasis3 & 199 & $0.36,0.64$ & $67.65,10.93$ & 198 & $0.3,0.7$ & $68.58,10.07$ \\
\hline PNC & 631 & $0.52,0.48$ & $14.53,3.38$ & 631 & $0.52,0.48$ & $14.53,3.42$ \\
\hline TOP & 187 & $0.52,0.48$ & $33.7,9.5$ & 188 & $0.36,0.64$ & $33.25,9.72$ \\
\hline ukb-11025.0 & 1867 & $0.53,0.47$ & $62.21,7.45$ & 1868 & $0.51,0.49$ & $62.43,7.49$ \\
\hline ukb-11027.0 & 1117 & $0.53,0.47$ & $63.24,7.47$ & 1117 & $0.56,0.44$ & $63.06,7.39$ \\
\hline UMich_CWS & 14 & $0.64,0.36$ & $5.44,1.18$ & 15 & $0.53,0.47$ & $5.24,1.13$ \\
\hline UMich_IMPs & 107 & $0.52,0.48$ & $12.96,3.54$ & 107 & $0.58,0.42$ & $12.78,3.3$ \\
\hline UMich_MTwins & 300 & $0.48,0.52$ & $14.37,2.04$ & 300 & $0.44,0.56$ & $14.19,2.06$ \\
\hline UMich_SAD & 57 & $0.35,0.65$ & $26.33,7.65$ & 57 & $0.4,0.6$ & $24.25,6.82$ \\
\hline UMich_SZG & 22 & $0.45,0.55$ & $35.73,9.82$ & 23 & $0.52,0.48$ & $28.17,8.54$ \\
\hline
\end{tabular}

Appendix 0 Table 5. Full Test Set Evaluation Metrics

\begin{tabular}{lrrrr}
\hline ROI & EV & MSLL & Skew & Kurtosis \\
\hline Ih_G\&S_frontomargin_thickness & 0.27 & -0.16 & 0.07 & 0.92 \\
Ih_G\&S_occipital_inf_thickness & 0.21 & -0.11 & 0.10 & 0.30 \\
Ih_G\&S_paracentral_thickness & 0.21 & -0.10 & -0.05 & 0.25 \\
\hline & \multicolumn{4}{c}{ Continued on next page } \\
\hline
\end{tabular}


bioRxiv preprint doi: https://doi.org/10.1101/2021.08.08.455487; this version posted Auqust 9, 2021. The copyright holder for this preprint (which was not certified by peer review) is the author/funder, who has granted bioRxiv a license to display the preprint in perpetuity. It is made available under aCC-BY 4.0 International license.

Appendix 0 Table 5. Full Test Set Evaluation Metrics

\begin{tabular}{|c|c|c|c|c|}
\hline ROI & EV & MSLL & Skew & Kurtosis \\
\hline Ih_G\&S_subcentral_thickness & 0.26 & -0.13 & 0.02 & 0.35 \\
\hline Ih_G\&S_transv_frontopol_thickness & 0.25 & -0.13 & 0.20 & 1.09 \\
\hline Ih_G\&S_cingul-Ant_thickness & 0.28 & -0.16 & 0.11 & 0.80 \\
\hline Ih_G\&S_cingul-Mid-Ant_thickness & 0.23 & -0.11 & -0.44 & 0.90 \\
\hline Ih_G\&S_cingul-Mid-Post_thickness & 0.33 & -0.20 & -0.13 & 0.64 \\
\hline Ih_G_cingul-Post-dorsal_thickness & 0.30 & -0.15 & -0.10 & 0.65 \\
\hline Ih_G_cingul-Post-ventral_thickness & 0.35 & -0.21 & 0.02 & 0.18 \\
\hline Ih_G_cuneus_thickness & 0.39 & -0.25 & 0.45 & 1.61 \\
\hline Ih_G_front_inf-Opercular_thickness & 0.32 & -0.17 & -0.14 & 0.65 \\
\hline Ih_G_front_inf-Orbital_thickness & 0.27 & -0.14 & -0.08 & 0.82 \\
\hline Ih_G_front_inf-Triangul_thickness & 0.35 & -0.20 & -0.05 & 0.68 \\
\hline Ih_G_front_middle_thickness & 0.39 & -0.25 & -0.26 & 0.82 \\
\hline Ih_G_front_sup_thickness & 0.39 & -0.23 & -0.18 & 0.62 \\
\hline Ih_G_Ins_Ig\&S_cent_ins_thickness & 0.13 & -0.07 & 0.05 & 0.15 \\
\hline Ih_G_insular_short_thickness & 0.12 & -0.06 & -0.22 & 0.36 \\
\hline Ih_G_occipital_middle_thickness & 0.23 & -0.13 & -0.24 & 0.98 \\
\hline Ih_G_occipital_sup_thickness & 0.22 & -0.12 & 0.17 & 0.41 \\
\hline Ih_G_oc-temp_lat-fusifor_thickness & 0.26 & -0.12 & -0.22 & 0.66 \\
\hline Ih_G_oc-temp_med-Lingual_thickness & 0.49 & -0.35 & 0.19 & 0.57 \\
\hline Ih_G_oc-temp_med-Parahip_thickness & 0.14 & -0.07 & -0.21 & 0.24 \\
\hline Ih_G_orbital_thickness & 0.32 & -0.19 & -0.09 & 0.70 \\
\hline Ih_G_pariet_inf-Angular_thickness & 0.37 & -0.23 & -0.32 & 1.15 \\
\hline Ih_G_pariet_inf-Supramar_thickness & 0.34 & -0.20 & -0.21 & 0.65 \\
\hline Ih_G_parietal_sup_thickness & 0.35 & -0.22 & -0.14 & 0.55 \\
\hline Ih_G_postcentral_thickness & 0.22 & -0.12 & 0.11 & 0.38 \\
\hline Ih_G_precentral_thickness & 0.23 & -0.12 & -0.50 & 1.04 \\
\hline Ih_G_precuneus_thickness & 0.34 & -0.21 & -0.09 & 0.43 \\
\hline Ih_G_rectus_thickness & 0.24 & -0.11 & -0.11 & 0.99 \\
\hline Ih_G_subcallosal_thickness & 0.23 & -0.13 & 0.06 & 0.41 \\
\hline Ih_G_temp_sup-G_T_transv_thickness & 0.24 & -0.13 & 0.16 & 0.24 \\
\hline Ih_G_temp_sup-Lateral_thickness & 0.23 & -0.11 & -0.08 & 0.36 \\
\hline Ih_G_temp_sup-Plan_polar_thickness & 0.14 & -0.08 & -0.27 & 0.41 \\
\hline Ih_G_temp_sup-Plan_tempo_thickness & 0.25 & -0.12 & -0.04 & 0.33 \\
\hline Ih_G_temporal_inf_thickness & 0.29 & -0.14 & -0.09 & 0.51 \\
\hline Ih_G_temporal_middle_thickness & 0.29 & -0.17 & -0.24 & 0.78 \\
\hline Ih_Lat_Fis-ant-Horizont_thickness & 0.16 & -0.07 & 0.88 & 2.04 \\
\hline Ih_Lat_Fis-ant-Vertical_thickness & 0.21 & -0.10 & 0.46 & 1.22 \\
\hline Ih_Lat_Fis-post_thickness & 0.30 & -0.17 & 0.07 & 0.73 \\
\hline Ih_Pole_occipital_thickness & 0.15 & -0.07 & 0.16 & 0.63 \\
\hline Ih_Pole_temporal_thickness & 0.18 & -0.09 & -0.31 & 0.77 \\
\hline Ih_S_calcarine_thickness & 0.51 & -0.36 & 0.30 & 0.97 \\
\hline Ih_S_central_thickness & 0.30 & -0.16 & -0.03 & 0.63 \\
\hline Ih_S_cingul-Marginalis_thickness & 0.36 & -0.22 & -0.10 & 0.66 \\
\hline Ih_S_circular_insula_ant_thickness & 0.23 & -0.10 & 0.02 & 0.60 \\
\hline Ih_S_circular_insula_inf_thickness & 0.28 & -0.14 & 0.05 & 0.28 \\
\hline Ih_S_circular_insula_sup_thickness & 0.39 & -0.23 & -0.22 & 0.97 \\
\hline
\end{tabular}

Continued on next page 
bioRxiv preprint doi: https://doi.org/10.1101/2021.08.08.455487; this version posted Auqust 9, 2021. The copyright holder for this preprint (which was not certified by peer review) is the author/funder, who has granted bioRxiv a license to display the preprint in perpetuity. It is made available under aCC-BY 4.0 International license.

Appendix 0 Table 5. Full Test Set Evaluation Metrics

\begin{tabular}{|c|c|c|c|c|}
\hline ROI & EV & MSLL & Skew & Kurtosis \\
\hline Ih_S_collat_transv_ant_thickness & 0.11 & -0.04 & 0.27 & 1.02 \\
\hline Ih_S_collat_transv_post_thickness & 0.19 & -0.10 & 0.45 & 0.86 \\
\hline Ih_S_front_inf_thickness & 0.42 & -0.25 & -0.18 & 1.03 \\
\hline Ih_S_front_middle_thickness & 0.39 & -0.23 & 0.08 & 1.40 \\
\hline Ih_S_front_sup_thickness & 0.43 & -0.27 & -0.29 & 1.11 \\
\hline Ih_S_interm_prim-Jensen_thickness & 0.16 & -0.08 & 1.08 & 2.10 \\
\hline Ih_S_intrapariet\&P_trans_thickness & 0.41 & -0.25 & -0.19 & 1.08 \\
\hline Ih_S_oc_middle\&Lunatus_thickness & 0.27 & -0.15 & 0.23 & 1.56 \\
\hline Ih_S_oc_sup\&transversal_thickness & 0.32 & -0.18 & -0.06 & 0.67 \\
\hline Ih_S_occipital_ant_thickness & 0.19 & -0.10 & 0.17 & 0.55 \\
\hline Ih_S_oc-temp_lat_thickness & 0.19 & -0.10 & 0.22 & 0.77 \\
\hline Ih_S_oc-temp_med\&Lingual_thickness & 0.32 & -0.19 & 0.05 & 0.31 \\
\hline Ih_S_orbital_lateral_thickness & 0.24 & -0.11 & 0.70 & 2.36 \\
\hline Ih_S_orbital_med-olfact_thickness & 0.20 & -0.11 & 0.76 & 3.94 \\
\hline Ih_S_orbital-H_Shaped_thickness & 0.35 & -0.19 & 0.11 & 0.75 \\
\hline Ih_S_parieto_occipital_thickness & 0.38 & -0.22 & -0.03 & 0.52 \\
\hline Ih_S_pericallosal_thickness & 0.10 & -0.05 & 0.67 & 0.88 \\
\hline Ih_S_postcentral_thickness & 0.41 & -0.25 & -0.10 & 0.68 \\
\hline Ih_S_precentral-inf-part_thickness & 0.36 & -0.21 & -0.28 & 0.92 \\
\hline Ih_S_precentral-sup-part_thickness & 0.29 & -0.17 & -0.29 & 0.85 \\
\hline Ih_S_suborbital_thickness & 0.13 & -0.06 & 0.64 & 1.53 \\
\hline Ih_S_subparietal_thickness & 0.29 & -0.16 & 0.11 & 0.97 \\
\hline Ih_S_temporal_inf_thickness & 0.20 & -0.11 & 0.14 & 0.79 \\
\hline Ih_S_temporal_sup_thickness & 0.41 & -0.25 & -0.22 & 0.68 \\
\hline Ih_S_temporal_transverse_thickness & 0.13 & -0.07 & 0.49 & 0.20 \\
\hline Ih_MeanThickness_thickness & 0.46 & -0.29 & -0.30 & 0.62 \\
\hline rh_G\&S_frontomargin_thickness & 0.27 & -0.13 & 0.36 & 1.60 \\
\hline rh_G\&S_occipital_inf_thickness & 0.12 & -0.04 & 0.12 & 0.23 \\
\hline rh_G\&S_paracentral_thickness & 0.21 & -0.10 & 0.05 & 0.40 \\
\hline rh_G\&S_subcentral_thickness & 0.25 & -0.12 & 0.05 & 0.27 \\
\hline rh_G\&S_transv_frontopol_thickness & 0.29 & -0.15 & 0.25 & 1.11 \\
\hline rh_G\&S_cingul-Ant_thickness & 0.36 & -0.21 & 0.06 & 1.17 \\
\hline rh_G\&S_cingul-Mid-Ant_thickness & 0.25 & -0.13 & -0.36 & 0.92 \\
\hline rh_G\&S_cingul-Mid-Post_thickness & 0.31 & -0.18 & -0.16 & 0.63 \\
\hline rh_G_cingul-Post-dorsal_thickness & 0.30 & -0.17 & -0.39 & 1.59 \\
\hline rh_G_cingul-Post-ventral_thickness & 0.25 & -0.14 & 0.00 & 0.31 \\
\hline rh_G_cuneus_thickness & 0.50 & -0.36 & 0.52 & 2.00 \\
\hline rh_G_front_inf-Opercular_thickness & 0.33 & -0.18 & -0.14 & 0.55 \\
\hline rh_G_front_inf-Orbital_thickness & 0.25 & -0.13 & 0.00 & 0.66 \\
\hline rh_G_front_inf-Triangul_thickness & 0.35 & -0.19 & -0.06 & 0.65 \\
\hline rh_G_front_middle_thickness & 0.39 & -0.25 & -0.24 & 0.96 \\
\hline rh_G_front_sup_thickness & 0.38 & -0.24 & -0.23 & 0.69 \\
\hline rh_G_Ins_Ig\&S_cent_ins_thickness & 0.09 & -0.04 & 0.02 & 0.02 \\
\hline rh_G_insular_short_thickness & 0.13 & -0.07 & -0.01 & 0.11 \\
\hline rh_G_occipital_middle_thickness & 0.25 & -0.14 & -0.21 & 1.03 \\
\hline rh_G_occipital_sup_thickness & 0.26 & -0.15 & 0.08 & 0.47 \\
\hline
\end{tabular}

Continued on next page 
bioRxiv preprint doi: https://doi.org/10.1101/2021.08.08.455487; this version posted Auqust 9, 2021. The copyright holder for this preprint (which was not certified by peer review) is the author/funder, who has granted bioRxiv a license to display the preprint in perpetuity. It is made available under aCC-BY 4.0 International license.

Appendix 0 Table 5. Full Test Set Evaluation Metrics

\begin{tabular}{|c|c|c|c|c|}
\hline ROI & EV & MSLL & Skew & Kurtosis \\
\hline rh_G_oc-temp_lat-fusifor_thickness & 0.20 & -0.08 & -0.11 & 0.47 \\
\hline rh_G_oc-temp_med-Lingual_thickness & 0.54 & -0.41 & 0.20 & 0.59 \\
\hline rh_G_oc-temp_med-Parahip_thickness & 0.15 & -0.07 & -0.20 & 0.29 \\
\hline rh_G_orbital_thickness & 0.29 & -0.15 & -0.04 & 0.47 \\
\hline rh_G_pariet_inf-Angular_thickness & 0.33 & -0.20 & -0.30 & 0.91 \\
\hline rh_G_pariet_inf-Supramar_thickness & 0.32 & -0.19 & -0.28 & 0.71 \\
\hline rh_G_parietal_sup_thickness & 0.34 & -0.20 & -0.08 & 0.46 \\
\hline rh_G_postcentral_thickness & 0.20 & -0.11 & 0.09 & 0.49 \\
\hline rh_G_precentral_thickness & 0.21 & -0.10 & -0.58 & 1.14 \\
\hline rh_G_precuneus_thickness & 0.33 & -0.20 & 0.00 & 0.42 \\
\hline rh_G_rectus_thickness & 0.21 & -0.09 & 0.07 & 1.04 \\
\hline rh_G_subcallosal_thickness & 0.11 & -0.05 & 0.39 & 0.48 \\
\hline rh_G_temp_sup-G_T_transv_thickness & 0.21 & -0.11 & 0.10 & 0.38 \\
\hline rh_G_temp_sup-Lateral_thickness & 0.25 & -0.12 & -0.13 & 0.58 \\
\hline rh_G_temp_sup-Plan_polar_thickness & 0.15 & -0.07 & -0.13 & 0.19 \\
\hline rh_G_temp_sup-Plan_tempo_thickness & 0.27 & -0.13 & -0.02 & 0.40 \\
\hline rh_G_temporal_inf_thickness & 0.25 & -0.14 & -0.17 & 0.50 \\
\hline rh_G_temporal_middle_thickness & 0.31 & -0.17 & -0.26 & 0.95 \\
\hline rh_Lat_Fis-ant-Horizont_thickness & 0.22 & -0.10 & 0.46 & 1.08 \\
\hline rh_Lat_Fis-ant-Vertical_thickness & 0.17 & -0.08 & 0.68 & 1.71 \\
\hline rh_Lat_Fis-post_thickness & 0.33 & -0.19 & 0.04 & 1.10 \\
\hline rh_Pole_occipital_thickne & 0.19 & -0.10 & 0.20 & 0.40 \\
\hline rh_Pole_temporal_thickness & 0.17 & -0.08 & -0.31 & 0.86 \\
\hline rh_S_calcarine_thickness & 0.51 & -0.36 & 0.32 & 1.14 \\
\hline rh_S_central_thickness & 0.29 & -0.16 & 0.04 & 0.70 \\
\hline rh_S_cingul-Marginalis_thickness & 0.36 & -0.21 & -0.13 & 0.75 \\
\hline rh_S_circular_insula_ant_thickness & 0.21 & -0.09 & 0.12 & 0.42 \\
\hline rh_S_circular_insula_inf_thickness & 0.26 & -0.13 & 0.15 & 0.41 \\
\hline rh_S_circular_insula_sup_thickness & 0.38 & -0.23 & -0.19 & 0.91 \\
\hline rh_S_collat_transv_ant_thickness & 0.14 & -0.05 & 0.57 & 1.52 \\
\hline rh_S_collat_transv_post_thickness & 0.20 & -0.10 & 0.28 & 0.73 \\
\hline rh_S_front_inf_thickness & 0.41 & -0.25 & -0.26 & 1.47 \\
\hline rh_S_front_middle_thickness & 0.43 & -0.26 & -0.13 & 1.32 \\
\hline rh_S_front_sup_thickness & 0.42 & -0.25 & -0.28 & 1.26 \\
\hline rh_S_interm_prim-Jensen_thickness & 0.25 & -0.12 & 0.47 & 1.29 \\
\hline rh_S_intrapariet\&P_trans_thickness & 0.41 & -0.25 & -0.14 & 0.85 \\
\hline rh_S_oc_middle\&Lunatus_thickness & 0.23 & -0.12 & 0.32 & 1.20 \\
\hline rh_S_oc_sup\&transversal_thickness & 0.31 & -0.17 & 0.05 & 0.98 \\
\hline rh_S_occipital_ant_thickness & 0.17 & -0.09 & 0.24 & 0.39 \\
\hline rh_S_oc-temp_lat_thickness & 0.17 & -0.08 & 0.41 & 1.05 \\
\hline rh_S_oc-temp_med\&Lingual_thickness & 0.33 & -0.20 & 0.08 & 0.59 \\
\hline rh_S_orbital_lateral_thickness & 0.29 & -0.16 & 0.48 & 2.19 \\
\hline rh_S_orbital_med-olfact_thickness & 0.24 & -0.13 & 0.49 & 2.50 \\
\hline rh_S_orbital-H_Shaped_thickness & 0.39 & -0.21 & 0.09 & 0.91 \\
\hline rh_S_parieto_occipital_thickness & 0.34 & -0.20 & -0.05 & 0.53 \\
\hline rh_S_pericallosal_thickness & 0.10 & -0.05 & 0.82 & 1.07 \\
\hline
\end{tabular}

Continued on next page 
bioRxiv preprint doi: https://doi.org/10.1101/2021.08.08.455487; this version posted August 9, 2021. The copyright holder for this preprint (which was not certified by peer review) is the author/funder, who has granted bioRxiv a license to display the preprint in perpetuity. It is made available under aCC-BY 4.0 International license.

Appendix 0 Table 5. Full Test Set Evaluation Metrics

\begin{tabular}{|c|c|c|c|c|}
\hline $\mathrm{ROI}$ & EV & MSLL & Skew & Kurtosis \\
\hline rh_S_postcentral_thickness & 0.39 & -0.23 & -0.08 & 0.50 \\
\hline rh_S_precentral-inf-part_thickness & 0.33 & -0.19 & -0.37 & 1.19 \\
\hline rh_S_precentral-sup-part_thickness & 0.26 & -0.15 & -0.55 & 1.79 \\
\hline rh_S_suborbital_thickness & 0.11 & -0.06 & 0.31 & 0.21 \\
\hline rh_S_subparietal_thickness & 0.27 & -0.15 & 0.18 & 0.76 \\
\hline rh_S_temporal_inf_thickness & 0.18 & -0.10 & 0.20 & 1.13 \\
\hline rh_S_temporal_sup_thickness & 0.41 & -0.25 & -0.18 & 0.70 \\
\hline rh_S_temporal_transverse_thickness & 0.14 & -0.07 & 0.25 & 0.18 \\
\hline rh_MeanThickness_thickness & 0.45 & -0.29 & -0.24 & 0.59 \\
\hline Left-Lateral-Ventricle & 0.40 & -0.34 & 0.47 & 0.54 \\
\hline Left-Inf-Lat-Vent & 0.30 & -0.19 & 0.26 & 0.79 \\
\hline Left-Cerebellum-White-Matter & 0.31 & -0.20 & 0.32 & 2.15 \\
\hline Left-Cerebellum-Cortex & 0.34 & -0.20 & -0.33 & 2.69 \\
\hline Left-Thalamus-Proper & 0.58 & -0.43 & 0.13 & 1.57 \\
\hline Left-Caudate & 0.32 & -0.19 & 0.06 & 1.24 \\
\hline Left-Putamen & 0.46 & -0.30 & -0.22 & 2.02 \\
\hline Left-Pallidum & 0.42 & -0.29 & -0.08 & 1.15 \\
\hline 3rd-Ventricle & 0.47 & -0.37 & 0.68 & 1.15 \\
\hline 4th-Ventricle & 0.09 & -0.05 & 0.35 & 0.48 \\
\hline Brain-Stem & 0.37 & -0.24 & 0.03 & 1.04 \\
\hline Left-Hippocampus & 0.26 & -0.15 & -0.18 & 1.48 \\
\hline Left-Amygdala & 0.28 & -0.16 & -0.16 & 1.40 \\
\hline CSF & 0.28 & -0.18 & 0.57 & 1.36 \\
\hline Left-Accumbens-area & 0.60 & -0.43 & -0.20 & 1.23 \\
\hline Left-VentralDC & 0.32 & -0.19 & 0.10 & 0.55 \\
\hline Left-vessel & 0.17 & -0.09 & 0.12 & 0.72 \\
\hline Left-choroid-plexus & 0.60 & -0.42 & -0.10 & 0.21 \\
\hline Right-Lateral-Ventricle & 0.41 & -0.35 & 0.46 & 0.56 \\
\hline Right-Inf-Lat-Vent & 0.25 & -0.14 & 0.14 & 0.71 \\
\hline Right-Cerebellum-White-Matter & 0.29 & -0.19 & 0.57 & 2.83 \\
\hline Right-Cerebellum-Cortex & 0.32 & -0.20 & -0.31 & 2.77 \\
\hline Right-Thalamus-Proper & 0.58 & -0.42 & 0.08 & 0.94 \\
\hline Right-Caudate & 0.33 & -0.19 & 0.08 & 1.09 \\
\hline Right-Putamen & 0.43 & -0.28 & -0.16 & 2.11 \\
\hline Right-Pallidum & 0.35 & -0.22 & -0.03 & 0.80 \\
\hline Right-Hippocampus & 0.25 & -0.15 & -0.14 & 1.02 \\
\hline Right-Amygdala & 0.29 & -0.17 & -0.10 & 1.12 \\
\hline Right-Accumbens-area & 0.42 & -0.27 & -0.04 & 1.02 \\
\hline Right-VentralDC & 0.33 & -0.19 & 0.12 & 0.64 \\
\hline Right-vessel & 0.24 & -0.11 & 0.08 & 1.40 \\
\hline Right-choroid-plexus & 0.68 & -0.45 & -0.04 & 0.25 \\
\hline SubCortGrayVol & 0.61 & -0.42 & -0.07 & 0.97 \\
\hline TotalGrayVol & 0.60 & -0.45 & -0.16 & 1.40 \\
\hline SupraTentorialVol & 0.35 & -0.21 & -0.03 & 0.52 \\
\hline SupraTentorialVoINotVent & 0.37 & -0.23 & -0.05 & 0.54 \\
\hline avg_thickness & 0.48 & -0.31 & -0.27 & 0.71 \\
\hline
\end{tabular}

Continued on next page 
bioRxiv preprint doi: https://doi.org/10.1101/2021.08.08.455487; this version posted Auqust 9, 2021. The copyright holder for this preprint (which was not certified by peer review) is the author/funder, who has granted bioRxiv a license to display the preprint in perpetuity. It is made available under aCC-BY 4.0 International license.

Appendix 0 Table 5. Full Test Set Evaluation Metrics

\begin{tabular}{lrrrr}
\hline ROI & EV & MSLL & Skew & Kurtosis \\
\hline EstimatedTotallntraCranialVol & 0.33 & -0.20 & -0.38 & 2.41 \\
\hline
\end{tabular}

Appendix 0 Table 6. mQC Test Set Evaluation Metrics

\begin{tabular}{|c|c|c|c|c|}
\hline ROI & EV & MSLL & Skew & Kurtosis \\
\hline Ih_G\&S_frontomargin_thickness & 0.26 & -0.15 & 0.24 & 1.18 \\
\hline Ih_G\&S_occipital_inf_thickness & 0.19 & -0.11 & 0.06 & 0.41 \\
\hline Ih_G\&S_paracentral_thickness & 0.29 & -0.16 & -0.02 & 0.48 \\
\hline Ih_G\&S_subcentral_thickness & 0.27 & -0.15 & -0.01 & 0.48 \\
\hline Ih_G\&S_transv_frontopol_thickness & 0.31 & -0.16 & 0.27 & 1.43 \\
\hline Ih_G\&S_cingul-Ant_thickness & 0.27 & -0.15 & 0.09 & 0.80 \\
\hline Ih_G\&S_cingul-Mid-Ant_thickness & 0.29 & -0.17 & -0.35 & 1.26 \\
\hline Ih_G\&S_cingul-Mid-Post_thickness & 0.37 & -0.23 & -0.08 & 0.67 \\
\hline Ih_G_cingul-Post-dorsal_thickness & 0.33 & -0.18 & -0.04 & 0.50 \\
\hline Ih_G_cingul-Post-ventral_thickness & 0.37 & -0.23 & 0.00 & 0.27 \\
\hline Ih_G_cuneus_thickness & 0.41 & -0.26 & 0.24 & 0.58 \\
\hline Ih_G_front_inf-Opercular_thickness & 0.38 & -0.24 & -0.12 & 0.66 \\
\hline Ih_G_front_inf-Orbital_thickness & 0.34 & -0.19 & -0.06 & 0.90 \\
\hline Ih_G_front_inf-Triangul_thickness & 0.42 & -0.26 & -0.01 & 0.57 \\
\hline Ih_G_front_middle_thickness & 0.47 & -0.32 & -0.17 & 0.70 \\
\hline Ih_G_front_sup_thickness & 0.45 & -0.30 & -0.12 & 0.49 \\
\hline Ih_G_Ins_Ig\&S_cent_ins_thickness & 0.13 & -0.07 & 0.04 & 0.15 \\
\hline Ih_G_insular_short_thickness & 0.15 & -0.08 & -0.24 & 0.33 \\
\hline Ih_G_occipital_middle_thickness & 0.27 & -0.16 & -0.32 & 1.45 \\
\hline Ih_G_occipital_sup_thickness & 0.27 & -0.16 & 0.15 & 0.46 \\
\hline Ih_G_oc-temp_lat-fusifor_thickness & 0.26 & -0.17 & -0.15 & 0.62 \\
\hline Ih_G_oc-temp_med-Lingual_thickness & 0.50 & -0.37 & 0.10 & 0.43 \\
\hline Ih_G_oc-temp_med-Parahip_thickness & 0.14 & -0.08 & -0.12 & 0.26 \\
\hline Ih_G_orbital_thickness & 0.36 & -0.23 & -0.01 & 0.49 \\
\hline Ih_G_pariet_inf-Angular_thickness & 0.44 & -0.30 & -0.36 & 1.37 \\
\hline Ih_G_pariet_inf-Supramar_thickness & 0.38 & -0.24 & -0.21 & 0.77 \\
\hline Ih_G_parietal_sup_thickness & 0.45 & -0.30 & -0.14 & 0.63 \\
\hline Ih_G_postcentral_thickness & 0.28 & -0.16 & 0.15 & 0.64 \\
\hline Ih_G_precentral_thickness & 0.26 & -0.14 & -0.49 & 1.38 \\
\hline Ih_G_precuneus_thickness & 0.41 & -0.26 & -0.06 & 0.52 \\
\hline Ih_G_rectus_thickness & 0.24 & -0.13 & -0.18 & 0.86 \\
\hline Ih_G_subcallosal_thickness & 0.24 & -0.15 & 0.03 & 0.43 \\
\hline Ih_G_temp_sup-G_T_transv_thickness & 0.30 & -0.17 & 0.05 & 0.21 \\
\hline Ih_G_temp_sup-Lateral_thickness & 0.25 & -0.12 & -0.05 & 0.28 \\
\hline Ih_G_temp_sup-Plan_polar_thickness & 0.18 & -0.12 & -0.19 & 0.55 \\
\hline Ih_G_temp_sup-Plan_tempo_thickness & 0.27 & -0.15 & -0.04 & 0.40 \\
\hline Ih_G_temporal_inf_thickness & 0.25 & -0.12 & -0.14 & 0.53 \\
\hline Ih_G_temporal_middle_thickness & 0.34 & -0.21 & -0.20 & 0.94 \\
\hline Ih_Lat_Fis-ant-Horizont_thickness & 0.18 & -0.08 & 0.73 & 1.73 \\
\hline Ih_Lat_Fis-ant-Vertical_thickness & 0.20 & -0.10 & 0.45 & 1.21 \\
\hline
\end{tabular}


bioRxiv preprint doi: https://doi.org/10.1101/2021.08.08.455487; this version posted Auqust 9, 2021. The copyright holder for this preprint (which was not certified by peer review) is the author/funder, who has granted bioRxiv a license to display the preprint in perpetuity. It is made available under aCC-BY 4.0 International license.

Appendix 0 Table 6. mQC Test Set Evaluation Metrics

\begin{tabular}{|c|c|c|c|c|}
\hline ROI & EV & MSLL & Skew & Kurtosis \\
\hline Ih_Lat_Fis-post_thickness & 0.31 & -0.18 & 0.01 & 0.65 \\
\hline Ih_Pole_occipital_thickness & 0.19 & -0.10 & 0.10 & 0.77 \\
\hline Ih_Pole_temporal_thickness & 0.13 & -0.06 & -0.21 & 0.63 \\
\hline Ih_S_calcarine_thickness & 0.53 & -0.39 & 0.19 & 0.35 \\
\hline Ih_S_central_thickness & 0.31 & -0.18 & -0.07 & 0.76 \\
\hline Ih_S_cingul-Marginalis_thickness & 0.42 & -0.27 & -0.15 & 0.77 \\
\hline Ih_S_circular_insula_ant_thickness & 0.22 & -0.12 & -0.14 & 0.73 \\
\hline Ih_S_circular_insula_inf_thickness & 0.30 & -0.17 & 0.09 & 0.41 \\
\hline Ih_S_circular_insula_sup_thickness & 0.37 & -0.23 & -0.29 & 0.98 \\
\hline Ih_S_collat_transv_ant_thickness & 0.10 & -0.05 & 0.46 & 1.59 \\
\hline Ih_S_collat_transv_post_thickness & 0.20 & -0.11 & 0.40 & 1.20 \\
\hline Ih_S_front_inf_thickness & 0.40 & -0.25 & -0.35 & 1.29 \\
\hline Ih_S_front_middle_thickness & 0.36 & -0.22 & -0.04 & 1.11 \\
\hline Ih_S_front_sup_thickness & 0.40 & -0.26 & -0.36 & 1.40 \\
\hline Ih_S_interm_prim-Jensen_thickness & 0.13 & -0.06 & 1.19 & 2.64 \\
\hline Ih_S_intrapariet\&P_trans_thickness & 0.43 & -0.27 & -0.33 & 1.20 \\
\hline Ih_S_oc_middle\&Lunatus_thickness & 0.24 & -0.14 & 0.05 & 1.21 \\
\hline Ih_S_oc_sup\&transversal_thickness & 0.32 & -0.19 & -0.17 & 0.71 \\
\hline Ih_S_occipital_ant_thickness & 0.18 & -0.10 & 0.15 & 0.52 \\
\hline Ih_S_oc-temp_lat_thickness & 0.16 & -0.08 & 0.30 & 0.91 \\
\hline Ih_S_oc-temp_med\&Lingual_thickness & 0.33 & -0.20 & 0.11 & 0.47 \\
\hline Ih_S_orbital_lateral_thickness & 0.21 & -0.11 & 0.59 & 1.87 \\
\hline Ih_S_orbital_med-olfact_thickness & 0.21 & -0.08 & 0.97 & 5.28 \\
\hline Ih_S_orbital-H_Shaped_thickness & 0.32 & -0.23 & 0.14 & 0.62 \\
\hline Ih_S_parieto_occipital_thickness & 0.40 & -0.25 & -0.07 & 0.70 \\
\hline Ih_S_pericallosal_thickness & 0.11 & -0.08 & 0.70 & 1.01 \\
\hline Ih_S_postcentral_thickness & 0.44 & -0.28 & -0.18 & 0.88 \\
\hline Ih_S_precentral-inf-part_thickness & 0.34 & -0.21 & -0.27 & 1.15 \\
\hline Ih_S_precentral-sup-part_thickness & 0.28 & -0.17 & -0.29 & 1.16 \\
\hline Ih_S_suborbital_thickness & 0.13 & -0.05 & 0.57 & 1.45 \\
\hline Ih_S_subparietal_thickness & 0.30 & -0.18 & 0.03 & 0.85 \\
\hline Ih_S_temporal_inf_thickness & 0.20 & -0.11 & 0.32 & 1.32 \\
\hline Ih_S_temporal_sup_thickness & 0.42 & -0.27 & -0.19 & 0.79 \\
\hline Ih_S_temporal_transverse_thickness & 0.14 & -0.07 & 0.57 & 0.49 \\
\hline Ih_MeanThickness_thickness & 0.50 & -0.34 & -0.35 & 0.88 \\
\hline rh_G\&S_frontomargin_thickness & 0.25 & -0.14 & 0.22 & 1.07 \\
\hline rh_G\&S_occipital_inf_thickness & 0.13 & -0.05 & 0.14 & 0.31 \\
\hline rh_G\&S_paracentral_thickness & 0.29 & -0.16 & 0.03 & 0.57 \\
\hline rh_G\&S_subcentral_thickness & 0.26 & -0.14 & 0.09 & 0.32 \\
\hline rh_G\&S_transv_frontopol_thickness & 0.33 & -0.18 & 0.22 & 0.86 \\
\hline rh_G\&S_cingul-Ant_thickness & 0.33 & -0.19 & -0.02 & 1.00 \\
\hline rh_G\&S_cingul-Mid-Ant_thickness & 0.31 & -0.18 & -0.25 & 0.82 \\
\hline rh_G\&S_cingul-Mid-Post_thickness & 0.33 & -0.20 & -0.15 & 0.66 \\
\hline rh_G_cingul-Post-dorsal_thickness & 0.31 & -0.18 & -0.39 & 1.41 \\
\hline rh_G_cingul-Post-ventral_thickness & 0.24 & -0.14 & -0.04 & 0.43 \\
\hline rh_G_cuneus_thickness & 0.51 & -0.38 & 0.45 & 1.66 \\
\hline
\end{tabular}

Continued on next page 
bioRxiv preprint doi: https://doi.org/10.1101/2021.08.08.455487; this version posted Auqust 9, 2021. The copyright holder for this preprint (which was not certified by peer review) is the author/funder, who has granted bioRxiv a license to display the preprint in perpetuity. It is made available under aCC-BY 4.0 International license.

Appendix 0 Table 6. mQC Test Set Evaluation Metrics

\begin{tabular}{|c|c|c|c|c|}
\hline $\mathrm{ROI}$ & EV & MSLL & Skew & Kurtosis \\
\hline rh_G_front_inf-Opercular_thickness & 0.39 & -0.25 & -0.06 & 0.49 \\
\hline rh_G_front_inf-Orbital_thickness & 0.31 & -0.18 & 0.01 & 0.64 \\
\hline rh_G_front_inf-Triangul_thickness & 0.40 & -0.25 & -0.03 & 0.56 \\
\hline rh_G_front_middle_thickness & 0.47 & -0.32 & -0.30 & 0.87 \\
\hline rh_G_front_sup_thickness & 0.43 & -0.28 & -0.26 & 0.67 \\
\hline rh_G_Ins_Ig\&S_cent_ins_thickness & 0.11 & -0.05 & 0.05 & 0.04 \\
\hline rh_G_insular_short_thickness & 0.14 & -0.09 & -0.02 & 0.10 \\
\hline rh_G_occipital_middle_thickness & 0.32 & -0.19 & -0.24 & 1.28 \\
\hline rh_G_occipital_sup_thickness & 0.33 & -0.21 & -0.02 & 0.47 \\
\hline rh_G_oc-temp_lat-fusifor_thickness & 0.22 & -0.12 & -0.01 & 0.49 \\
\hline rh_G_oc-temp_med-Lingual_thickness & 0.53 & -0.42 & 0.25 & 0.90 \\
\hline rh_G_oc-temp_med-Parahip_thickness & 0.15 & -0.08 & -0.08 & 0.22 \\
\hline rh_G_orbital_thickness & 0.32 & -0.17 & 0.04 & 0.50 \\
\hline rh_G_pariet_inf-Angular_thickness & 0.40 & -0.23 & -0.29 & 1.00 \\
\hline rh_G_pariet_inf-Supramar_thickness & 0.36 & -0.22 & -0.19 & 0.45 \\
\hline rh_G_parietal_sup_thickness & 0.43 & -0.28 & -0.07 & 0.41 \\
\hline rh_G_postcentral_thickness & 0.26 & -0.14 & 0.16 & 0.61 \\
\hline rh_G_precentral_thickness & 0.24 & -0.14 & -0.67 & 1.73 \\
\hline rh_G_precuneus_thickness & 0.40 & -0.25 & -0.01 & 0.45 \\
\hline rh_G_rectus_thickness & 0.20 & -0.09 & 0.00 & 0.96 \\
\hline rh_G_subcallosal_thickness & 0.11 & -0.06 & 0.31 & 0.17 \\
\hline rh_G_temp_sup-G_T_transv_thickness & 0.26 & -0.14 & 0.07 & 0.41 \\
\hline rh_G_temp_sup-Lateral_thickness & 0.26 & -0.12 & -0.08 & 0.42 \\
\hline rh_G_temp_sup-Plan_polar_thickness & 0.17 & -0.10 & -0.04 & 0.27 \\
\hline rh_G_temp_sup-Plan_tempo_thickness & 0.27 & -0.15 & 0.03 & 0.41 \\
\hline rh_G_temporal_inf_thickness & 0.23 & -0.13 & -0.05 & 0.48 \\
\hline rh_G_temporal_middle_thickness & 0.36 & -0.22 & -0.20 & 0.70 \\
\hline rh_Lat_Fis-ant-Horizont_thickness & 0.23 & -0.12 & 0.34 & 1.04 \\
\hline rh_Lat_Fis-ant-Vertical_thickness & 0.14 & -0.07 & 0.65 & 1.48 \\
\hline rh_Lat_Fis-post_thickness & 0.33 & -0.20 & -0.02 & 1.14 \\
\hline rh_Pole_occipital_thickness & 0.24 & -0.13 & 0.12 & 0.47 \\
\hline rh_Pole_temporal_thickness & 0.14 & -0.05 & -0.15 & 0.54 \\
\hline rh_S_calcarine_thickness & 0.52 & -0.38 & 0.33 & 1.28 \\
\hline rh_S_central_thickness & 0.33 & -0.19 & 0.04 & 0.94 \\
\hline rh_S_cingul-Marginalis_thickness & 0.40 & -0.24 & -0.20 & 0.75 \\
\hline rh_S_circular_insula_ant_thickness & 0.19 & -0.09 & 0.01 & 0.49 \\
\hline rh_S_circular_insula_inf_thickness & 0.27 & -0.15 & 0.20 & 0.64 \\
\hline rh_S_circular_insula_sup_thickness & 0.35 & -0.21 & -0.24 & 0.92 \\
\hline rh_S_collat_transv_ant_thickness & 0.12 & -0.05 & 0.56 & 1.43 \\
\hline rh_S_collat_transv_post_thickness & 0.21 & -0.11 & 0.31 & 0.87 \\
\hline rh_S_front_inf_thickness & 0.39 & -0.24 & -0.43 & 1.77 \\
\hline rh_S_front_middle_thickness & 0.39 & -0.24 & -0.31 & 1.31 \\
\hline rh_S_front_sup_thickness & 0.37 & -0.24 & -0.32 & 1.43 \\
\hline rh_S_interm_prim-Jensen_thickness & 0.24 & -0.13 & 0.57 & 1.72 \\
\hline rh_S_intrapariet\&P_trans_thickness & 0.43 & -0.27 & -0.21 & 0.92 \\
\hline rh_S_oc_middle\&Lunatus_thickness & 0.21 & -0.12 & 0.14 & 0.74 \\
\hline
\end{tabular}


bioRxiv preprint doi: https://doi.org/10.1101/2021.08.08.455487; this version posted Auqust 9, 2021. The copyright holder for this preprint (which was not certified by peer review) is the author/funder, who has granted bioRxiv a license to display the preprint in perpetuity. It is made available under aCC-BY 4.0 International license.

Appendix 0 Table 6. mQC Test Set Evaluation Metrics

\begin{tabular}{|c|c|c|c|c|}
\hline $\mathrm{ROI}$ & EV & MSLL & Skew & Kurtosis \\
\hline rh_S_oc_sup\&transversal_thickness & 0.31 & -0.18 & -0.02 & 0.92 \\
\hline rh_S_occipital_ant_thickness & 0.18 & -0.09 & 0.28 & 0.60 \\
\hline rh_S_oc-temp_lat_thickness & 0.13 & -0.07 & 0.47 & 1.53 \\
\hline rh_S_oc-temp_med\&Lingual_thickness & 0.36 & -0.25 & 0.16 & 0.44 \\
\hline rh_S_orbital_lateral_thickness & 0.25 & -0.14 & 0.13 & 1.71 \\
\hline rh_S_orbital_med-olfact_thickness & 0.20 & -0.08 & 0.70 & 3.90 \\
\hline rh_S_orbital-H_Shaped_thickness & 0.33 & -0.21 & 0.15 & 0.83 \\
\hline rh_S_parieto_occipital_thickness & 0.39 & -0.24 & -0.12 & 0.61 \\
\hline rh_S_pericallosal_thickness & 0.11 & -0.09 & 0.87 & 1.37 \\
\hline rh_S_postcentral_thickness & 0.42 & -0.26 & -0.08 & 0.76 \\
\hline rh_S_precentral-inf-part_thickness & 0.30 & -0.18 & -0.43 & 1.41 \\
\hline rh_S_precentral-sup-part_thickness & 0.24 & -0.14 & -0.57 & 1.78 \\
\hline rh_S_suborbital_thickness & 0.09 & -0.05 & 0.66 & 0.75 \\
\hline rh_S_subparietal_thickness & 0.28 & -0.17 & 0.07 & 0.71 \\
\hline rh_S_temporal_inf_thickness & 0.17 & -0.09 & 0.18 & 0.86 \\
\hline rh_S_temporal_sup_thickness & 0.42 & -0.26 & -0.17 & 0.65 \\
\hline rh_S_temporal_transverse_thickness & 0.15 & -0.08 & 0.20 & 0.28 \\
\hline rh_MeanThickness_thickness & 0.49 & -0.34 & -0.29 & 0.73 \\
\hline Left-Lateral-Ventricle & 0.42 & -0.43 & 0.60 & 0.71 \\
\hline Left-Inf-Lat-Vent & 0.26 & -0.17 & 0.30 & 0.86 \\
\hline Left-Cerebellum-White-Matter & 0.25 & -0.16 & 0.53 & 2.21 \\
\hline Left-Cerebellum-Cortex & 0.31 & -0.19 & -0.40 & 4.09 \\
\hline Left-Thalamus-Proper & 0.61 & -0.54 & 0.23 & 1.15 \\
\hline Left-Caudate & 0.32 & -0.23 & 0.12 & 0.59 \\
\hline Left-Putamen & 0.49 & -0.38 & -0.18 & 0.96 \\
\hline Left-Pallidum & 0.42 & -0.30 & -0.04 & 0.73 \\
\hline 3rd-Ventricle & 0.50 & -0.50 & 0.73 & 1.34 \\
\hline 4th-Ventricle & 0.08 & -0.04 & 0.32 & 0.34 \\
\hline Brain-Stem & 0.38 & -0.26 & 0.08 & 0.36 \\
\hline Left-Hippocampus & 0.26 & -0.14 & -0.08 & 0.80 \\
\hline Left-Amygdala & 0.29 & -0.16 & -0.07 & 0.82 \\
\hline CSF & 0.28 & -0.20 & 0.69 & 1.97 \\
\hline Left-Accumbens-area & 0.60 & -0.49 & -0.04 & 0.39 \\
\hline Left-VentralDC & 0.29 & -0.17 & 0.16 & 0.33 \\
\hline Left-vessel & 0.14 & -0.08 & 0.10 & 0.73 \\
\hline Left-choroid-plexus & 0.57 & -0.42 & -0.02 & 0.43 \\
\hline Right-Lateral-Ventricle & 0.43 & -0.44 & 0.57 & 0.65 \\
\hline Right-Inf-Lat-Vent & 0.20 & -0.12 & 0.16 & 0.76 \\
\hline Right-Cerebellum-White-Matter & 0.28 & -0.19 & 0.69 & 2.88 \\
\hline Right-Cerebellum-Cortex & 0.29 & -0.17 & -0.38 & 4.57 \\
\hline Right-Thalamus-Proper & 0.58 & -0.48 & 0.18 & 0.77 \\
\hline Right-Caudate & 0.33 & -0.23 & 0.17 & 0.57 \\
\hline Right-Putamen & 0.45 & -0.34 & -0.08 & 0.81 \\
\hline Right-Pallidum & 0.29 & -0.18 & 0.05 & 0.60 \\
\hline Right-Hippocampus & 0.25 & -0.15 & -0.06 & 0.61 \\
\hline Right-Amygdala & 0.29 & -0.17 & -0.01 & 0.38 \\
\hline
\end{tabular}


bioRxiv preprint doi: https://doi.org/10.1101/2021.08.08.455487; this version posted August 9, 2021. The copyright holder for this preprint (which was not certified by peer review) is the author/funder, who has granted bioRxiv a license to display the preprint in perpetuity. It is made available under aCC-BY 4.0 International license.

Appendix 0 Table 6. mQC Test Set Evaluation Metrics

\begin{tabular}{lrrrr}
\hline ROI & EV & MSLL & Skew & Kurtosis \\
\hline Right-Accumbens-area & 0.36 & -0.26 & 0.07 & 0.50 \\
Right-VentralDC & 0.30 & -0.17 & 0.17 & 0.50 \\
Right-vessel & 0.23 & -0.11 & 0.14 & 1.27 \\
Right-choroid-plexus & 0.61 & -0.40 & 0.00 & 0.43 \\
SubCortGrayVol & 0.47 & -0.34 & 0.00 & 0.23 \\
TotalGrayVol & 0.62 & -0.49 & -0.10 & 0.22 \\
SupraTentorialVol & 0.35 & -0.20 & 0.00 & 0.18 \\
SupraTentorialVoINotVent & 0.37 & -0.23 & -0.01 & 0.17 \\
avg_thickness & 0.51 & -0.36 & -0.32 & 0.82 \\
EstimatedTotalIntraCranialVol & 0.36 & -0.22 & -0.28 & 1.54 \\
\hline
\end{tabular}

Appendix 0 Table 7. Patient Test Set Evaluation Metrics

\begin{tabular}{lrrrr}
\hline ROI & EV & MSLL & Skew & Kurtosis \\
\hline Ih_G\&S_frontomargin & 0.45 & -0.94 & 0.69 & 3.04 \\
Ih_G\&S_occipital_inf & 0.38 & -0.78 & 0.15 & 0.67 \\
Ih_G\&S_paracentral & 0.39 & -0.37 & 0.00 & 0.32 \\
Ih_G\&S_subcentral & 0.46 & -0.95 & -0.05 & 0.76 \\
Ih_G\&S_transv_frontopol & 0.39 & -0.52 & 0.75 & 2.31 \\
Ih_G\&S_cingul-Ant & 0.49 & -1.05 & 0.29 & 1.35 \\
Ih_G\&S_cingul-Mid-Ant & 0.43 & -0.35 & 0.00 & 1.07 \\
Ih_G\&S_cingul-Mid-Post & 0.58 & -0.99 & 0.11 & 0.76 \\
Ih_G_cingul-Post-dorsal & 0.53 & -0.91 & -0.11 & 1.35 \\
Ih_G_cingul-Post-ventral & 0.48 & -0.34 & 0.13 & 0.72 \\
Ih_G_cuneus & 0.52 & -0.41 & 0.66 & 1.85 \\
Ih_G_front_inf-Opercular & 0.53 & -1.10 & -0.16 & 0.96 \\
Ih_G_front_inf-Orbital & 0.41 & -0.55 & -0.10 & 1.09 \\
Ih_G_front_inf-Triangul & 0.56 & -0.96 & -0.08 & 1.01 \\
Ih_G_front_middle & 0.52 & -1.12 & -0.18 & 1.03 \\
Ih_G_front_sup & 0.54 & -1.02 & -0.22 & 1.25 \\
Ih_G_Ins_Ig\&S_cent_ins & 0.26 & -0.14 & -0.17 & 0.83 \\
Ih_G_insular_short & 0.28 & -0.18 & -0.29 & 1.84 \\
Ih_G_occipital_middle & 0.47 & -0.79 & -0.31 & 1.49 \\
Ih_G_occipital_sup & 0.36 & -0.42 & 0.32 & 0.78 \\
Ih_G_oc-temp_lat-fusifor & 0.40 & -0.97 & -0.26 & 1.79 \\
Ih_G_oc-temp_med-Lingual & 0.56 & -0.38 & 0.56 & 2.02 \\
Ih_G_oc-temp_med-Parahip & 0.24 & -0.17 & -0.41 & 0.89 \\
Ih_G_orbital & 0.58 & -0.79 & -0.11 & 1.29 \\
Ih_G_pariet_inf-Angular & 0.57 & -1.06 & -0.38 & 2.15 \\
Ih_G_pariet_inf-Supramar & 0.55 & -1.23 & -0.28 & 1.27 \\
Ih_G_parietal_sup & 0.48 & -1.06 & -0.07 & 1.17 \\
Ih_G_postcentral & 0.37 & -0.66 & 0.12 & 1.03 \\
Ih_G_precentral & 0.43 & -0.61 & -0.59 & 1.59 \\
Ih_G_precuneus & 0.58 & -1.03 & -0.06 & 0.69 \\
Ih_G_rectus & 0.35 & -0.65 & 0.89 & 5.08 \\
\hline & & Continued on next & \\
& & & & \\
& & &
\end{tabular}


bioRxiv preprint doi: https://doi.org/10.1101/2021.08.08.455487; this version posted August 9, 2021. The copyright holder for this preprint (which was not certified by peer review) is the author/funder, who has granted bioRxiv a license to display the preprint in perpetuity. It is made available under aCC-BY 4.0 International license.

Appendix 0 Table 7. Patient Test Set Evaluation Metrics

\begin{tabular}{|c|c|c|c|c|}
\hline ROI & EV & MSLL & Skew & Kurtosis \\
\hline Ih_G_subcallosal & 0.25 & -0.14 & 0.00 & 0.78 \\
\hline Ih_G_temp_sup-G_T_transv & 0.39 & -0.44 & 0.11 & 0.13 \\
\hline Ih_G_temp_sup-Lateral & 0.41 & -0.60 & -0.27 & 1.14 \\
\hline Ih_G_temp_sup-Plan_polar & 0.33 & -0.22 & -0.49 & 1.06 \\
\hline Ih_G_temp_sup-Plan_tempo & 0.45 & -0.86 & 0.03 & 0.46 \\
\hline Ih_G_temporal_inf & 0.31 & -0.96 & -0.33 & 1.41 \\
\hline Ih_G_temporal_middle & 0.45 & -0.71 & -0.42 & 1.50 \\
\hline Ih_Lat_Fis-ant-Horizont & 0.39 & -0.64 & 0.72 & 1.41 \\
\hline Ih_Lat_Fis-ant-Vertical & 0.39 & -0.90 & 0.60 & 1.42 \\
\hline Ih_Lat_Fis-post & 0.60 & -1.04 & 0.15 & 0.38 \\
\hline Ih_Pole_occipital & 0.34 & -0.26 & 0.74 & 3.35 \\
\hline Ih_Pole_temporal & 0.22 & -0.50 & -0.80 & 2.17 \\
\hline Ih_S_calcarine & 0.65 & -0.69 & 0.79 & 2.83 \\
\hline Ih_S_central & 0.59 & -0.96 & 0.27 & 1.98 \\
\hline Ih_S_cingul-Marginalis & 0.58 & -1.21 & 0.20 & 0.92 \\
\hline Ih_S_circular_insula_ant & 0.49 & -0.85 & 0.13 & 0.64 \\
\hline Ih_S_circular_insula_inf & 0.53 & -0.57 & 0.04 & 0.66 \\
\hline Ih_S_circular_insula_sup & 0.65 & -1.45 & -0.02 & 0.49 \\
\hline Ih_S_collat_transv_ant & 0.32 & -0.48 & 0.47 & 1.42 \\
\hline Ih_S_collat_transv_post & 0.37 & -0.56 & 0.81 & 3.55 \\
\hline Ih_S_front_inf & 0.65 & -1.69 & 0.08 & 0.84 \\
\hline Ih_S_front_middle & 0.53 & -1.35 & 0.54 & 2.68 \\
\hline Ih_S_front_sup & 0.52 & -1.55 & -0.02 & 1.28 \\
\hline Ih_S_interm_prim-Jensen & 0.25 & -0.52 & 1.16 & 2.69 \\
\hline Ih_S_intrapariet\&P_trans & 0.62 & -1.66 & 0.08 & 1.31 \\
\hline Ih_S_oc_middle\&Lunatus & 0.41 & -0.89 & 0.84 & 3.98 \\
\hline Ih_S_oc_sup\&transversal & 0.50 & -1.12 & 0.25 & 0.76 \\
\hline Ih_S_occipital_ant & 0.40 & -0.75 & 0.79 & 5.01 \\
\hline In_S_oc-temp_lat & 0.37 & -0.80 & 0.64 & 3.14 \\
\hline Ih_S_oc-temp_med\&Lingual & 0.56 & -0.75 & 0.06 & 0.84 \\
\hline Ih_S_orbital_lateral & 0.39 & -0.80 & 1.03 & 3.80 \\
\hline Ih_S_orbital_med-olfact & 0.39 & -0.41 & 1.73 & 8.42 \\
\hline Ih_S_orbital-H_Shaped & 0.53 & -1.14 & 0.16 & 1.27 \\
\hline Ih_S_parieto_occipital & 0.64 & -1.08 & 0.19 & 0.50 \\
\hline Ih_S_pericallosal & 0.24 & -0.13 & 0.92 & 1.75 \\
\hline Ih_S_postcentral & 0.63 & -1.53 & 0.09 & 0.51 \\
\hline Ih_S_precentral-inf-part & 0.58 & -1.57 & -0.01 & 0.83 \\
\hline Ih_S_precentral-sup-part & 0.48 & -1.14 & -0.21 & 0.90 \\
\hline Ih_S_suborbital & 0.32 & -0.38 & 1.31 & 6.09 \\
\hline Ih_S_subparietal & 0.51 & -1.12 & 0.56 & 2.81 \\
\hline Ih_S_temporal_inf & 0.45 & -0.66 & 0.54 & 5.47 \\
\hline Ih_S_temporal_sup & 0.67 & -1.45 & -0.23 & 0.73 \\
\hline Ih_S_temporal_transverse & 0.30 & -0.32 & 0.31 & 0.61 \\
\hline Ih_MeanThickness & 0.71 & -1.60 & -0.31 & 1.10 \\
\hline rh_G\&S_frontomargin & 0.42 & -0.80 & 1.16 & 5.18 \\
\hline rh_G\&S_occipital_inf & 0.30 & -0.53 & 0.21 & 0.49 \\
\hline
\end{tabular}

Continued on next page 
bioRxiv preprint doi: https://doi.org/10.1101/2021.08.08.455487; this version posted August 9, 2021. The copyright holder for this preprint (which was not certified by peer review) is the author/funder, who has granted bioRxiv a license to display the preprint in perpetuity. It is made available under aCC-BY 4.0 International license.

Appendix 0 Table 7. Patient Test Set Evaluation Metrics

\begin{tabular}{|c|c|c|c|c|}
\hline ROI & EV & MSLL & Skew & Kurtosis \\
\hline rh_G\&S_paracentral & 0.38 & -0.35 & 0.18 & 0.76 \\
\hline rh_G\&S_subcentral & 0.45 & -0.85 & 0.13 & 0.27 \\
\hline rh_G\&S_transv_frontopol & 0.42 & -0.62 & 0.69 & 2.37 \\
\hline rh_G\&S_cingul-Ant & 0.62 & -1.29 & 0.40 & 2.06 \\
\hline rh_G\&S_cingul-Mid-Ant & 0.53 & -0.70 & 0.12 & 2.43 \\
\hline rh_G\&S_cingul-Mid-Post & 0.59 & -1.07 & 0.18 & 0.79 \\
\hline rh_G_cingul-Post-dorsal & 0.51 & -0.99 & -0.37 & 2.26 \\
\hline rh_G_cingul-Post-ventral & 0.26 & -0.16 & 0.11 & 0.49 \\
\hline rh_G_cuneus & 0.46 & -0.31 & 0.90 & 3.93 \\
\hline rh_G_front_inf-Opercular & 0.51 & -1.05 & 0.02 & 0.50 \\
\hline rh_G_front_inf-Orbital & 0.39 & -0.50 & 0.16 & 0.86 \\
\hline rh_G_front_inf-Triangul & 0.51 & -0.82 & 0.18 & 1.45 \\
\hline rh_G_front_middle & 0.53 & -1.00 & -0.38 & 1.33 \\
\hline rh_G_front_sup & 0.56 & -0.99 & -0.18 & 1.39 \\
\hline rh_G_Ins_lg\&S_cent_ins & 0.21 & -0.11 & -0.07 & 0.45 \\
\hline rh_G_insular_short & 0.25 & -0.14 & -0.06 & 0.08 \\
\hline rh_G_occipital_middle & 0.48 & -0.91 & -0.23 & 1.89 \\
\hline rh_G_occipital_sup & 0.41 & -0.46 & 0.05 & 0.95 \\
\hline rh_G_oc-temp_lat-fusifor & 0.38 & -0.71 & -0.15 & 1.09 \\
\hline rh_G_oc-temp_med-Lingual & 0.50 & -0.35 & 0.66 & 2.67 \\
\hline rh_G_oc-temp_med-Parahip & 0.27 & -0.20 & -0.42 & 0.77 \\
\hline rh_G_orbital & 0.54 & -0.68 & 0.05 & 0.70 \\
\hline rh_G_pariet_inf-Angular & 0.53 & -1.01 & -0.38 & 1.72 \\
\hline rh_G_pariet_inf-Supramar & 0.53 & -1.16 & -0.29 & 0.92 \\
\hline rh_G_parietal_sup & 0.43 & -0.98 & -0.11 & 0.91 \\
\hline rh_G_postcentral & 0.36 & -0.53 & 0.19 & 0.40 \\
\hline rh_G_precentral & 0.43 & -0.52 & -0.69 & 1.66 \\
\hline rh_G_precuneus & 0.55 & -0.98 & -0.02 & 0.44 \\
\hline rh_G_rectus & 0.35 & -0.56 & 0.60 & 2.12 \\
\hline rh_G_subcallosal & 0.12 & -0.06 & 0.02 & 0.44 \\
\hline rh_G_temp_sup-G_T_transv & 0.41 & -0.47 & 0.12 & 0.17 \\
\hline rh_G_temp_sup-Lateral & 0.43 & -0.66 & -0.29 & 1.16 \\
\hline rh_G_temp_sup-Plan_polar & 0.37 & -0.27 & -0.19 & 0.81 \\
\hline rh_G_temp_sup-Plan_tempo & 0.50 & -1.00 & 0.09 & 0.25 \\
\hline rh_G_temporal_inf & 0.36 & -0.90 & -0.37 & 1.54 \\
\hline rh_G_temporal_middle & 0.43 & -0.81 & -0.38 & 1.23 \\
\hline rh_Lat_Fis-ant-Horizont & 0.43 & -0.83 & 0.62 & 1.68 \\
\hline rh_Lat_Fis-ant-Vertical & 0.30 & -0.64 & 0.84 & 2.23 \\
\hline rh_Lat_Fis-post & 0.61 & -1.07 & 0.04 & 0.35 \\
\hline rh_Pole_occipital & 0.41 & -0.26 & 0.51 & 1.54 \\
\hline rh_Pole_temporal & 0.24 & -0.46 & -0.79 & 2.02 \\
\hline rh_S_calcarine & 0.65 & -0.72 & 0.66 & 1.99 \\
\hline rh_S_central & 0.63 & -0.92 & 0.28 & 1.03 \\
\hline rh_S_cingul-Marginalis & 0.61 & -1.33 & 0.08 & 0.77 \\
\hline rh_S_circular_insula_ant & 0.42 & -0.76 & 0.34 & 1.12 \\
\hline rh_S_circular_insula_inf & 0.53 & -0.58 & 0.29 & 0.60 \\
\hline
\end{tabular}


bioRxiv preprint doi: https://doi.org/10.1101/2021.08.08.455487; this version posted August 9, 2021. The copyright holder for this preprint (which was not certified by peer review) is the author/funder, who has granted bioRxiv a license to display the preprint in perpetuity. It is made available under aCC-BY 4.0 International license.

Appendix 0 Table 7. Patient Test Set Evaluation Metrics

\begin{tabular}{|c|c|c|c|c|}
\hline ROI & $\mathrm{EV}$ & MSLL & Skew & Kurtosis \\
\hline rh_S_circular_insula_sup & 0.63 & -1.44 & 0.11 & 1.12 \\
\hline rh_S_collat_transv_ant & 0.33 & -0.62 & 0.48 & 1.46 \\
\hline rh_S_collat_transv_post & 0.40 & -0.59 & 0.51 & 1.40 \\
\hline rh_S_front_inf & 0.63 & -1.60 & 0.39 & 2.23 \\
\hline rh_S_front_middle & 0.58 & -1.43 & 0.46 & 1.66 \\
\hline rh_S_front_sup & 0.54 & -1.49 & -0.11 & 0.59 \\
\hline rh_S_interm_prim-Jensen & 0.42 & -0.99 & 0.44 & 1.51 \\
\hline rh_S_intrapariet\&P_trans & 0.60 & -1.57 & 0.10 & 0.83 \\
\hline rh_S_oc_middle\&Lunatus & 0.37 & -0.81 & 0.45 & 1.80 \\
\hline rh_S_oc_sup\&transversal & 0.49 & -1.03 & 0.12 & 0.96 \\
\hline rh_S_occipital_ant & 0.39 & -0.75 & 0.12 & 1.65 \\
\hline rh_S_oc-temp_lat & 0.36 & -0.76 & 0.34 & 2.53 \\
\hline rh_S_oc-temp_med\&Lingual & 0.52 & -0.57 & 0.05 & 0.72 \\
\hline rh_S_orbital_lateral & 0.45 & -0.98 & 1.28 & 7.26 \\
\hline rh_S_orbital_med-olfact & 0.49 & -0.63 & 0.79 & 3.40 \\
\hline rh_S_orbital-H_Shaped & 0.55 & -1.24 & 0.36 & 1.10 \\
\hline rh_S_parieto_occipital & 0.62 & -1.10 & 0.16 & 0.45 \\
\hline rh_S_pericallosal & 0.27 & -0.16 & 0.81 & 1.41 \\
\hline rh_S_postcentral & 0.61 & -1.38 & 0.14 & 0.37 \\
\hline rh_S_precentral-inf-part & 0.57 & -1.47 & -0.06 & 0.57 \\
\hline rh_S_precentral-sup-part & 0.45 & -0.96 & -0.34 & 1.31 \\
\hline rh_S_suborbital & 0.25 & -0.25 & 0.53 & 0.60 \\
\hline rh_S_subparietal & 0.52 & -1.04 & 0.24 & 0.54 \\
\hline rh_S_temporal_inf & 0.42 & -0.71 & 0.32 & 1.94 \\
\hline rh_S_temporal_sup & 0.63 & -1.57 & -0.19 & 0.83 \\
\hline rh_S_temporal_transverse & 0.32 & -0.35 & 0.36 & 1.16 \\
\hline MeanThickness & 0.71 & -1.54 & -0.18 & 0.84 \\
\hline Left-Lateral-Ventricle & 0.37 & -0.26 & 0.55 & 0.51 \\
\hline Left-Inf-Lat-Vent & 0.27 & -0.31 & 0.87 & 1.78 \\
\hline Left-Cerebellum-White-Matter & 0.16 & -0.22 & -0.65 & 4.87 \\
\hline Left-Cerebellum-Cortex & 0.27 & -0.18 & -1.75 & 14.02 \\
\hline Left-Thalamus-Proper & 0.40 & -0.22 & -0.62 & 8.90 \\
\hline Left-Caudate & 0.13 & -0.07 & -0.16 & 3.70 \\
\hline Left-Putamen & 0.33 & -0.18 & -0.85 & 5.61 \\
\hline Left-Pallidum & 0.47 & -0.44 & -0.57 & 5.08 \\
\hline 3rd-Ventricle & 0.38 & -0.22 & 0.79 & 1.34 \\
\hline 4th-Ventricle & 0.01 & 0.00 & 0.30 & 1.42 \\
\hline Brain-Stem & 0.13 & -0.06 & -0.64 & 6.30 \\
\hline Left-Hippocampus & 0.35 & -0.31 & -1.54 & 8.88 \\
\hline Left-Amygdala & 0.35 & -0.28 & -1.20 & 6.45 \\
\hline CSF & 0.26 & -0.16 & 0.50 & 2.88 \\
\hline Left-Accumbens-area & 0.51 & -0.53 & -0.75 & 4.13 \\
\hline Left-VentralDC & 0.40 & -0.30 & -0.64 & 7.99 \\
\hline Left-vessel & 0.35 & -0.28 & 0.00 & 1.58 \\
\hline Left-choroid-plexus & 0.73 & -0.55 & 0.20 & 1.13 \\
\hline Right-Lateral-Ventricle & 0.39 & -0.26 & 0.49 & 0.69 \\
\hline
\end{tabular}

Continued on next page 
bioRxiv preprint doi: https://doi.org/10.1101/2021.08.08.455487; this version posted Auqust 9, 2021. The copyright holder for this preprint (which was not certified by peer review) is the author/funder, who has granted bioRxiv a license to display the preprint in perpetuity. It is made available under aCC-BY 4.0 International license.

Appendix 0 Table 7. Patient Test Set Evaluation Metrics

\begin{tabular}{lrrrr}
\hline ROI & EV & MSLL & Skew & Kurtosis \\
\hline Right-Inf-Lat-Vent & 0.24 & -0.26 & 0.88 & 2.16 \\
Right-Cerebellum-White-Matter & 0.12 & -0.16 & -0.67 & 6.55 \\
Right-Cerebellum-Cortex & 0.25 & -0.22 & -1.80 & 16.41 \\
Right-Thalamus-Proper & 0.49 & -0.32 & -0.39 & 4.50 \\
Right-Caudate & 0.18 & -0.10 & 0.09 & 2.29 \\
Right-Putamen & 0.36 & -0.21 & -0.91 & 4.40 \\
Right-Pallidum & 0.39 & -0.38 & -0.45 & 3.92 \\
Right-Hippocampus & 0.37 & -0.31 & -1.12 & 4.22 \\
Right-Amygdala & 0.36 & -0.38 & -0.94 & 3.38 \\
Right-Accumbens-area & 0.38 & -0.23 & -0.48 & 1.92 \\
Right-VentralDC & 0.40 & -0.32 & -0.31 & 5.74 \\
Right-vessel & 0.38 & -0.25 & -0.31 & 2.34 \\
Right-choroid-plexus & 0.80 & -0.85 & 0.17 & 0.89 \\
SubCortGrayVol & 0.43 & -0.23 & -0.99 & 9.58 \\
TotalGrayVol & 0.54 & -0.52 & -0.37 & 2.99 \\
SupraTentorialVoINotVent & 0.33 & -0.27 & -0.06 & 1.69 \\
avg_thickness & 0.72 & -1.66 & -0.22 & 0.82 \\
EstimatedTotalIntraCranialVol & 0.26 & -0.16 & 0.23 & 1.33 \\
\hline
\end{tabular}

Appendix 0 Table 8. Transfer Test Set Evaluation Metrics

\begin{tabular}{lrrrr}
\hline ROI & EV & MSLL & Skew & Kurtosis \\
\hline Ih_G\&S_frontomargin_thickness & 0.20 & -0.62 & -0.26 & 0.66 \\
Ih_G\&S_occipital_inf_thickness & 0.02 & -0.43 & 0.66 & 2.95 \\
Ih_G\&S_paracentral_thickness & 0.26 & -0.37 & 0.31 & 1.72 \\
Ih_G\&S_subcentral_thickness & 0.20 & -0.44 & 0.22 & 0.61 \\
Ih_G\&S_transv_frontopol_thickness & 0.13 & -0.15 & 0.47 & 0.74 \\
Ih_G\&S_cingul-Ant_thickness & 0.20 & -0.42 & 0.52 & 1.24 \\
Ih_G\&S_cingul-Mid-Ant_thickness & 0.25 & -0.28 & 0.29 & 0.04 \\
Ih_G\&S_cingul-Mid-Post_thickness & 0.24 & -0.43 & -0.16 & 0.55 \\
Ih_G_cingul-Post-dorsal_thickness & 0.23 & -0.34 & -0.36 & 1.32 \\
Ih_G_cingul-Post-ventral_thickness & 0.08 & -0.08 & 0.38 & 0.79 \\
Ih_G_cuneus_thickness & 0.61 & -0.54 & 0.79 & 2.43 \\
Ih_G_front_inf-Opercular_thickness & 0.33 & -0.50 & 0.41 & 0.91 \\
Ih_G_front_inf-Orbital_thickness & 0.20 & -0.19 & 0.36 & 1.36 \\
Ih_G_front_inf-Triangul_thickness & 0.19 & -0.39 & 0.25 & 0.12 \\
Ih_G_front_middle_thickness & 0.31 & -0.58 & 0.38 & 1.08 \\
Ih_G_front_sup_thickness & 0.50 & -0.59 & 0.30 & 0.29 \\
Ih_G_Ins_I\&\&_cent_ins_thickness & 0.23 & -0.10 & -0.08 & 0.24 \\
Ih_G_insular_short_thickness & 0.33 & -0.16 & -0.01 & 0.60 \\
Ih_G_occipital_middlle_thickness & 0.22 & -0.51 & 0.10 & -0.05 \\
Ih_G_occipital_sup_thickness & 0.24 & -0.27 & 0.58 & 3.04 \\
Ih_G_oc-temp_lat-fusifor_thickness & 0.25 & -0.73 & 0.02 & 0.48 \\
Ih_G_oc-temp_med-Lingual_thickness & 0.52 & -0.46 & 0.32 & 0.15 \\
Ih_G_oc-temp_med-Parahip_thickness & 0.23 & -0.12 & 0.21 & 0.32 \\
\hline & & Continued on next page \\
\hline
\end{tabular}


bioRxiv preprint doi: https://doi.org/10.1101/2021.08.08.455487; this version posted Auqust 9, 2021. The copyright holder for this preprint (which was not certified by peer review) is the author/funder, who has granted bioRxiv a license to display the preprint in perpetuity. It is made available under aCC-BY 4.0 International license.

Appendix 0 Table 8. Transfer Test Set Evaluation Metrics

\begin{tabular}{|c|c|c|c|c|}
\hline $\mathrm{ROI}$ & EV & MSLL & Skew & Kurtosis \\
\hline Ih_G_orbital_thickness & 0.42 & -0.44 & -0.15 & 0.29 \\
\hline Ih_G_pariet_inf-Angular_thickness & 0.19 & -0.55 & 0.17 & 0.77 \\
\hline Ih_G_pariet_inf-Supramar_thickness & 0.17 & -0.70 & -0.02 & 0.62 \\
\hline Ih_G_parietal_sup_thickness & 0.26 & -0.78 & -0.06 & 1.43 \\
\hline Ih_G_postcentral_thickness & 0.14 & -0.59 & 0.19 & 0.61 \\
\hline Ih_G_precentral_thickness & 0.46 & -0.56 & -0.75 & 4.87 \\
\hline Ih_G_precuneus_thickness & 0.22 & -0.70 & 0.15 & 0.60 \\
\hline Ih_G_rectus_thickness & 0.25 & -0.53 & 0.68 & 1.98 \\
\hline Ih_G_subcallosal_thickness & 0.07 & 0.00 & 0.03 & 0.48 \\
\hline Ih_G_temp_sup-G_T_transv_thickness & 0.14 & -0.18 & 0.75 & 3.76 \\
\hline Ih_G_temp_sup-Lateral_thickness & 0.29 & -0.31 & -0.20 & 0.76 \\
\hline Ih_G_temp_sup-Plan_polar_thickness & 0.43 & -0.28 & -0.21 & 0.88 \\
\hline Ih_G_temp_sup-Plan_tempo_thickness & 0.19 & -0.53 & 0.48 & 1.16 \\
\hline Ih_G_temporal_inf_thickness & 0.52 & -1.24 & 0.35 & 0.45 \\
\hline Ih_G_temporal_middle_thickness & 0.23 & -0.26 & 0.03 & -0.15 \\
\hline Ih_Lat_Fis-ant-Horizont_thickness & 0.07 & -0.31 & 0.72 & 0.82 \\
\hline Ih_Lat_Fis-ant-Vertical_thickness & 0.19 & -0.41 & 0.53 & 3.39 \\
\hline Ih_Lat_Fis-post_thickness & 0.24 & -0.35 & 0.25 & 0.39 \\
\hline Ih_Pole_occipital_thickness & 0.48 & -0.33 & 0.51 & 2.73 \\
\hline Ih_Pole_temporal_thickness & 0.56 & -0.60 & 0.12 & 0.00 \\
\hline Ih_S_calcarine_thickness & 0.48 & -0.46 & 0.28 & 0.10 \\
\hline Ih_S_central_thickness & 0.40 & -0.82 & 0.44 & 0.47 \\
\hline Ih_S_cingul-Marginalis_thickness & 0.28 & -0.82 & 0.29 & 0.85 \\
\hline Ih_S_circular_insula_ant_thickness & 0.28 & -0.51 & 0.37 & 0.90 \\
\hline Ih_S_circular_insula_inf_thickness & 0.17 & -0.20 & 0.33 & 0.95 \\
\hline Ih_S_circular_insula_sup_thickness & 0.29 & -0.63 & 0.35 & 0.59 \\
\hline Ih_S_collat_transv_ant_thickness & 0.30 & -0.39 & 0.56 & 0.99 \\
\hline Ih_S_collat_transv_post_thickness & 0.10 & -0.37 & 0.96 & 2.42 \\
\hline Ih_S_front_inf_thickness & 0.36 & -1.20 & 0.18 & 0.66 \\
\hline Ih_S_front_middle_thickness & 0.26 & -0.98 & 0.41 & 0.59 \\
\hline Ih_S_front_sup_thickness & 0.43 & -1.03 & 0.19 & 0.64 \\
\hline Ih_S_interm_prim-Jensen_thickness & 0.00 & -0.25 & 1.28 & 2.68 \\
\hline Ih_S_intrapariet\&P_trans_thickness & 0.38 & -1.30 & -0.06 & 0.93 \\
\hline Ih_S_oc_middle\&Lunatus_thickness & 0.18 & -0.72 & 0.53 & 1.23 \\
\hline Ih_S_oc_sup\&transversal_thickness & 0.18 & -0.92 & 0.52 & 0.86 \\
\hline Ih_S_occipital_ant_thickness & 0.15 & -0.55 & 0.49 & 0.95 \\
\hline Ih_S_oc-temp_lat_thickness & 0.22 & -0.57 & 0.96 & 3.70 \\
\hline Ih_S_oc-temp_med\&Lingual_thickness & 0.24 & -0.25 & 1.03 & 3.51 \\
\hline Ih_S_orbital_lateral_thickness & 0.11 & -0.48 & 0.88 & 1.31 \\
\hline Ih_S_orbital_med-olfact_thickness & 0.45 & -0.36 & 0.73 & 1.45 \\
\hline Ih_S_orbital-H_Shaped_thickness & 0.22 & -0.56 & 0.58 & 1.69 \\
\hline Ih_S_parieto_occipital_thickness & 0.29 & -0.76 & 0.26 & 0.37 \\
\hline Ih_S_pericallosal_thickness & 0.13 & -0.04 & 0.85 & 1.45 \\
\hline Ih_S_postcentral_thickness & 0.35 & -1.12 & 0.38 & 0.68 \\
\hline Ih_S_precentral-inf-part_thickness & 0.30 & -0.89 & 0.13 & 1.01 \\
\hline Ih_S_precentral-sup-part_thickness & 0.25 & -0.55 & -0.41 & 1.67 \\
\hline
\end{tabular}

Continued on next page 
bioRxiv preprint doi: https://doi.org/10.1101/2021.08.08.455487; this version posted Auqust 9, 2021. The copyright holder for this preprint (which was not certified by peer review) is the author/funder, who has granted bioRxiv a license to display the preprint in perpetuity. It is made available under aCC-BY 4.0 International license.

Appendix 0 Table 8. Transfer Test Set Evaluation Metrics

\begin{tabular}{|c|c|c|c|c|}
\hline ROI & EV & MSLL & Skew & Kurtosis \\
\hline Ih_S_suborbital_thickness & 0.03 & -0.05 & 0.94 & 2.64 \\
\hline Ih_S_subparietal_thickness & 0.14 & -0.71 & 0.28 & 0.22 \\
\hline Ih_S_temporal_inf_thickness & 0.30 & -0.31 & 0.38 & 1.28 \\
\hline Ih_S_temporal_sup_thickness & 0.31 & -0.86 & 0.30 & 0.52 \\
\hline Ih_S_temporal_transverse_thickness & 0.07 & -0.11 & 0.43 & -0.18 \\
\hline Ih_MeanThickness_thickness & 0.37 & -1.00 & 0.10 & 0.53 \\
\hline rh_G\&S_frontomargin_thickness & 0.24 & -0.75 & 0.62 & 1.55 \\
\hline rh_G\&S_occipital_inf_thickness & 0.14 & -0.34 & 0.16 & 0.04 \\
\hline rh_G\&S_paracentral_thickness & 0.25 & -0.38 & 0.27 & 1.05 \\
\hline rh_G\&S_subcentral_thickness & 0.20 & -0.39 & 0.24 & 0.34 \\
\hline rh_G\&S_transv_frontopol_thickness & 0.21 & -0.34 & 0.27 & 1.76 \\
\hline rh_G\&S_cingul-Ant_thickness & 0.38 & -0.95 & 0.30 & 0.65 \\
\hline rh_G\&S_cingul-Mid-Ant_thickness & 0.33 & -0.44 & -0.04 & 0.76 \\
\hline rh_G\&S_cingul-Mid-Post_thickness & 0.25 & -0.50 & -0.01 & 0.95 \\
\hline rh_G_cingul-Post-dorsal_thickness & 0.14 & -0.46 & -0.12 & 1.48 \\
\hline rh_G_cingul-Post-ventral_thickness & 0.07 & -0.03 & 0.22 & 0.85 \\
\hline rh_G_cuneus_thickness & 0.56 & -0.45 & 0.36 & 0.47 \\
\hline rh_G_front_inf-Opercular_thickness & 0.29 & -0.47 & 0.04 & 1.12 \\
\hline rh_G_front_inf-Orbital_thickness & 0.14 & -0.18 & -0.16 & 1.11 \\
\hline rh_G_front_inf-Triangul_thickness & 0.23 & -0.38 & 0.28 & 0.31 \\
\hline rh_G_front_middle_thickness & 0.33 & -0.65 & 0.00 & 0.30 \\
\hline rh_G_front_sup_thickness & 0.44 & -0.62 & 0.22 & 0.80 \\
\hline rh_G_Ins_Ig\&S_cent_ins_thickness & 0.13 & -0.07 & -0.09 & -0.15 \\
\hline rh_G_insular_short_thickness & 0.18 & -0.06 & 0.09 & 0.11 \\
\hline rh_G_occipital_middle_thickness & 0.22 & -0.50 & 0.33 & 0.48 \\
\hline rh_G_occipital_sup_thickness & 0.23 & -0.37 & 0.26 & 1.06 \\
\hline rh_G_oc-temp_lat-fusifor_thickness & 0.36 & -0.59 & 0.43 & 0.67 \\
\hline rh_G_oc-temp_med-Lingual_thickness & 0.46 & -0.41 & 0.30 & 0.27 \\
\hline rh_G_oc-temp_med-Parahip_thickness & 0.49 & -0.31 & 0.17 & 0.46 \\
\hline rh_G_orbital_thickness & 0.36 & -0.46 & 0.18 & 0.33 \\
\hline rh_G_pariet_inf-Angular_thickness & 0.26 & -0.56 & -0.17 & 1.04 \\
\hline rh_G_pariet_inf-Supramar_thickness & 0.24 & -0.62 & 0.07 & 0.85 \\
\hline rh_G_parietal_sup_thickness & 0.22 & -0.71 & -0.13 & 0.82 \\
\hline rh_G_postcentral_thickness & 0.19 & -0.49 & 0.20 & 0.39 \\
\hline rh_G_precentral_thickness & 0.40 & -0.39 & -1.28 & 6.69 \\
\hline rh_G_precuneus_thickness & 0.24 & -0.72 & -0.17 & 1.05 \\
\hline rh_G_rectus_thickness & 0.17 & -0.55 & 0.06 & 0.76 \\
\hline rh_G_subcallosal_thickness & 0.06 & 0.01 & 0.35 & 0.39 \\
\hline rh_G_temp_sup-G_T_transv_thickness & 0.17 & -0.27 & -0.06 & -0.04 \\
\hline rh_G_temp_sup-Lateral_thickness & 0.31 & -0.42 & 0.08 & 0.22 \\
\hline rh_G_temp_sup-Plan_polar_thickness & 0.43 & -0.23 & -0.08 & 0.58 \\
\hline rh_G_temp_sup-Plan_tempo_thickness & 0.16 & -0.61 & 0.29 & 0.73 \\
\hline rh_G_temporal_inf_thickness & 0.60 & -1.13 & 0.00 & 0.29 \\
\hline rh_G_temporal_middle_thickness & 0.44 & -0.51 & 0.01 & 0.39 \\
\hline rh_Lat_Fis-ant-Horizont_thickness & 0.25 & -0.69 & 0.49 & 0.97 \\
\hline rh_Lat_Fis-ant-Vertical_thickness & 0.10 & -0.31 & 0.98 & 2.21 \\
\hline
\end{tabular}

Continued on next page 
bioRxiv preprint doi: https://doi.org/10.1101/2021.08.08.455487; this version posted Auqust 9, 2021. The copyright holder for this preprint (which was not certified by peer review) is the author/funder, who has granted bioRxiv a license to display the preprint in perpetuity. It is made available under aCC-BY 4.0 International license.

Appendix 0 Table 8. Transfer Test Set Evaluation Metrics

\begin{tabular}{|c|c|c|c|c|}
\hline $\mathrm{ROI}$ & EV & MSLL & Skew & Kurtosis \\
\hline rh_Lat_Fis-post_thickness & 0.23 & -0.38 & 0.22 & 0.00 \\
\hline rh_Pole_occipital_thickness & 0.49 & -0.34 & 0.36 & 1.42 \\
\hline rh_Pole_temporal_thickness & 0.52 & -0.55 & -0.03 & 0.14 \\
\hline rh_S_calcarine_thickness & 0.48 & -0.44 & 0.12 & 0.47 \\
\hline rh_S_central_thickness & 0.44 & -0.79 & 0.08 & 0.61 \\
\hline rh_S_cingul-Marginalis_thickness & 0.33 & -0.91 & 0.19 & 1.28 \\
\hline rh_S_circular_insula_ant_thickness & 0.25 & -0.50 & 0.42 & 1.03 \\
\hline rh_S_circular_insula_inf_thickness & 0.16 & -0.18 & 0.49 & 1.98 \\
\hline rh_S_circular_insula_sup_thickness & 0.32 & -0.72 & 0.45 & 1.10 \\
\hline rh_S_collat_transv_ant_thickness & 0.38 & -0.36 & 0.55 & 0.76 \\
\hline rh_S_collat_transv_post_thickness & 0.18 & -0.35 & 0.49 & 1.90 \\
\hline rh_S_front_inf_thickness & 0.27 & -1.09 & 0.15 & 0.54 \\
\hline rh_S_front_middle_thickness & 0.44 & -1.37 & 0.23 & 0.37 \\
\hline rh_S_front_sup_thickness & 0.43 & -1.07 & 0.20 & 0.26 \\
\hline rh_S_interm_prim-Jensen_thickness & 0.12 & -0.52 & 0.61 & 1.22 \\
\hline rh_S_intrapariet\&P_trans_thickness & 0.42 & -1.20 & -0.47 & 1.95 \\
\hline rh_S_oc_middle\&Lunatus_thickness & 0.09 & -0.50 & 0.95 & 3.38 \\
\hline rh_S_oc_sup\&transversal_thickness & 0.23 & -0.80 & 0.32 & 0.45 \\
\hline rh_S_occipital_ant_thickness & 0.20 & -0.53 & 0.25 & 0.46 \\
\hline rh_S_oc-temp_lat_thickness & 0.38 & -0.52 & 0.14 & 2.55 \\
\hline rh_S_oc-temp_med\&Lingual_thickness & 0.27 & -0.22 & 0.40 & 1.44 \\
\hline rh_S_orbital_lateral_thickness & 0.22 & -0.71 & 0.45 & 1.13 \\
\hline rh_S_orbital_med-olfact_thickness & 0.27 & -0.40 & 0.67 & 2.15 \\
\hline rh_S_orbital-H_Shaped_thickness & 0.27 & -1.14 & 0.40 & 0.61 \\
\hline rh_S_parieto_occipital_thickness & 0.33 & -0.78 & -0.07 & 0.02 \\
\hline rh_S_pericallosal_thickness & 0.20 & -0.08 & 1.09 & 3.12 \\
\hline rh_S_postcentral_thickness & 0.41 & -1.06 & 0.12 & 0.46 \\
\hline rh_S_precentral-inf-part_thickness & 0.30 & -0.87 & -0.14 & 2.32 \\
\hline rh_S_precentral-sup-part_thickness & 0.26 & -0.51 & -0.68 & 3.83 \\
\hline rh_S_suborbital_thickness & 0.15 & -0.22 & 0.56 & 0.63 \\
\hline rh_S_subparietal_thickness & 0.08 & -0.60 & -0.34 & 3.01 \\
\hline rh_S_temporal_inf_thickness & 0.45 & -0.50 & 0.72 & 1.74 \\
\hline rh_S_temporal_sup_thickness & 0.32 & -0.98 & 0.12 & 0.16 \\
\hline rh_S_temporal_transverse_thickness & 0.12 & -0.08 & 0.23 & 0.24 \\
\hline rh_MeanThickness_thickness & 0.39 & -1.05 & 0.03 & 0.52 \\
\hline Left-Lateral-Ventricle & 0.14 & -0.24 & 0.64 & 0.87 \\
\hline Left-Inf-Lat-Vent & 0.08 & -0.15 & 0.10 & 0.66 \\
\hline Left-Cerebellum-White-Matter & 0.21 & -0.19 & -0.10 & 3.01 \\
\hline Left-Cerebellum-Cortex & 0.38 & -0.29 & -0.84 & 2.33 \\
\hline Left-Thalamus-Proper & 0.39 & -0.29 & 0.12 & 0.11 \\
\hline Left-Caudate & 0.19 & -0.19 & 0.00 & -0.05 \\
\hline Left-Putamen & 0.36 & -0.34 & -0.22 & 0.95 \\
\hline Left-Pallidum & 0.34 & -0.23 & 0.19 & -0.21 \\
\hline 3rd-Ventricle & 0.27 & -0.29 & 0.96 & 3.49 \\
\hline 4th-Ventricle & 0.09 & 0.09 & 0.51 & 6.31 \\
\hline Brain-Stem & 0.33 & -0.17 & 0.06 & 0.59 \\
\hline
\end{tabular}

Continued on next page 
bioRxiv preprint doi: https://doi.org/10.1101/2021.08.08.455487; this version posted August 9, 2021. The copyright holder for this preprint (which was not certified by peer review) is the author/funder, who has granted bioRxiv a license to display the preprint in perpetuity. It is made available under aCC-BY 4.0 International license.

Appendix 0 Table 8. Transfer Test Set Evaluation Metrics

\begin{tabular}{lrrrr}
\hline ROI & EV & MSLL & Skew & Kurtosis \\
\hline Left-Hippocampus & 0.31 & -0.19 & 0.14 & 0.05 \\
Left-Amygdala & 0.33 & -0.23 & 0.33 & 0.41 \\
CSF & 0.08 & -0.11 & 0.89 & 2.50 \\
Left-Accumbens-area & 0.35 & -0.68 & 0.12 & 0.78 \\
Left-VentralDC & 0.36 & -0.27 & 0.29 & 0.59 \\
Left-vessel & 0.00 & 0.03 & -1.25 & 8.40 \\
Left-choroid-plexus & 0.08 & -0.28 & 0.10 & 0.84 \\
Right-Lateral-Ventricle & 0.16 & -0.26 & 0.76 & 1.64 \\
Right-Inf-Lat-Vent & 0.02 & -0.03 & -0.26 & 1.39 \\
Right-Cerebellum-White-Matter & 0.19 & -0.19 & -0.19 & 3.03 \\
Right-Cerebellum-Cortex & 0.41 & -0.37 & -0.80 & 2.55 \\
Right-Thalamus-Proper & 0.42 & -0.26 & 0.04 & 1.34 \\
Right-Caudate & 0.20 & -0.18 & 0.24 & 0.51 \\
Right-Putamen & 0.35 & -0.31 & -0.42 & 1.96 \\
Right-Pallidum & 0.24 & -0.17 & 0.11 & 0.10 \\
Right-Hippocampus & 0.29 & -0.19 & 0.13 & 0.00 \\
Right-Amygdala & 0.36 & -0.16 & 0.50 & 4.22 \\
Right-Accumbens-area & 0.35 & -0.49 & 0.20 & 0.52 \\
Right-VentralDC & 0.38 & -0.28 & 0.41 & 1.70 \\
Right-vessel & 0.08 & -0.02 & -0.63 & 5.50 \\
Right-choroid-plexus & 0.15 & -0.27 & -0.37 & 1.01 \\
SubCortGrayVol & 0.43 & -0.32 & 0.47 & 1.32 \\
TotalGrayVol & 0.51 & -0.36 & -0.23 & 0.49 \\
SupraTentorialVol & 0.39 & -0.19 & 0.00 & 0.28 \\
SupraTentorialVolNotVent & 0.39 & -0.18 & 0.03 & 0.31 \\
avg_thickness & 0.39 & -1.06 & 0.06 & 0.56 \\
EstimatedTotalIntraCranialVol & 0.46 & -0.37 & -0.17 & 0.92 \\
\hline & & & &
\end{tabular}

